\title{
Comparative genomic analysis of T-box regulatory systems in bacteria
}

\author{
ALEXEY G. VITRESCHAK, ${ }^{1}$ ANDREI A. MIRONOV,${ }^{1,2,3}$ VASSILY A. LYUBETSKY, ${ }^{1}$ and MIKHAIL S. GELFAND ${ }^{1,2}$ \\ ${ }^{1}$ Institute for Information Transmission Problems (The Kharkevich Institute), Russian Academy of Sciences, Moscow 127994, Russia \\ ${ }^{2}$ Department of Bioengineering and Bioinformatics, M.V. Lomonosov Moscow State University, Moscow 119992, Russia \\ ${ }^{3}$ State Scientific Center GosNIIGenetika, Moscow 117545, Russia
}

\begin{abstract}
T-box antitermination is one of the main mechanisms of regulation of genes involved in amino acid metabolism in Gram-positive bacteria. T-box regulatory sites consist of conserved sequence and RNA secondary structure elements. Using a set of known Tbox sites, we constructed the common pattern and used it to scan available bacterial genomes. New T-boxes were found in various Gram-positive bacteria, some Gram-negative bacteria ( $\delta$-proteobacteria), and some other bacterial groups (Deinococcales/Thermales, Chloroflexi, Dictyoglomi). The majority of T-box-regulated genes encode aminoacyl-tRNA synthetases. Two other groups of T-box-regulated genes are amino acid biosynthetic genes and transporters, as well as genes with unknown function. Analysis of candidate T-box sites resulted in new functional annotations. We assigned the amino acid specificity to a large number of candidate amino acid transporters and a possible function to amino acid biosynthesis genes. We then studied the evolution of the T-boxes. Analysis of the constructed phylogenetic trees demonstrated that in addition to the normal evolution consistent with the evolution of regulated genes, T-boxes may be duplicated, transferred to other genes, and change specificity. We observed several cases of recent T-box regulon expansion following the loss of a previously existing regulatory system, in particular, arginine regulon in Clostridium difficile and methionine regulon in Lactobacillaceae. Finally, we described a new structural class of T-boxes containing duplicated terminator-antiterminator elements and unusual reduced T-boxes regulating initiation of translation in the Actinobacteria.
\end{abstract}

Keywords: comparative genomics; amino acid biosynthesis and transport; T-box; antitermination; regulatory 5'-UTR mRNAs; bacteria

\section{INTRODUCTION}

The bacteria use a wide range of regulatory mechanisms to control gene expression. While the most common regulatory mechanism seems to be regulation of transcription by DNA-binding proteins (van Nimwegen 2003; Rodionov 2007), there are other important mechanisms, in particular, regulation of transcription (by premature termination) and translation (by interference with initiation) via formation of alternative RNA structures in 5'-untranslated gene regions (Henkin and Yanofsky 2002; Gutierrez-Preciado et al. 2005; Merino and Yanofsky 2005; Gelfand 2006; Weinberg et al. 2007). One particular set of genes that are frequently regulated by RNA-mediated mechanisms are the genes involved in metabolism of amino acids. In Gram-

Reprint requests to: Alexey G. Vitreschak, Institute for Information Transmission Problems (The Kharkevich Institute), Russian Academy of Sciences, Bolshoj Karetny pereulok 19, Moscow 127994, Russia; e-mail: 1_veter@mail.ru; fax: 10-095-6506579.

Article and publication are at http://www.rnajournal.org/cgi/doi/ 10.1261/rna.819308. negative bacteria, the concentration of amino acids is measured indirectly by the rate of translation of the leader peptide in transcription attenuators (Yanofsky 1988; Merino and Yanofsky 2005). In the Firmicutes, these genes may be regulated by riboswitches: S-boxes, also known as SAM riboswitches, regulate methionine and cysteine genes in response to concentration of a methionine derivative, $S$-adenosylmethionine (Grundy and Henkin 1998; Winkler et al. 2003; Rodionov et al. 2004); lysine riboswitches (LYSelements, or L-boxes) regulate lysine metabolism (Grundy et al. 2003; Rodionov et al. 2003; Sudarsan et al. 2003); glycine riboswitches regulate the glycine cleavage $g c v T$ operon (Mandal et al. 2004). Regulation of tryptophan biosynthesis and transport genes in Bacillus subtilis and a number of related bacteria is mediated by a RNA-binding protein, TRAP, but again this regulation involves formation of alternative RNA structures (Babitzke 2004).

However, the most frequent mechanism of RNAdependent regulation of amino acid operons in the Firmicutes seems to be the T-box regulatory system (Grundy and Henkin 2003; Merino and Yanofsky 2005). The T-box is an 
RNA structure that is capable of binding uncharged tRNA via an interaction between the highly conserved 5'-UGGN$3^{\prime}$ sequence of the T-box and the complementary $5^{\prime}$ NCCA-3' end of the tRNA (Putzer et al. 1995; van de Guchte et al. 1998; Grundy and Henkin 1993). The specificity of this binding is defined by base-pairing of the tRNA anticodon and the so-called specifier (anti-anti)codon in the T-box structure (Grundy et al. 1994, 1997b, 2002b; Marta et al. 1996). The bound uncharged tRNA stabilizes the antiterminator hairpin, which in turn prevents formation of the terminator and allows the gene to be expressed (Fig. 1A); the structural and kinetic details of this process are now understood in considerable detail (Luo et al. 1998; Pelchat and Lapointe 1999; Grundy et al. 2000; van de Guchte et al. 2001; Grundy and Henkin 2004; Fauzi et al. 2005; Yousef et al. 2005).

Initially identified in $B$. subtilis as a mechanism regulating expression of some aminoacyl-tRNA synthetase genes (Henkin et al. 1992; Putzer et al. 1992), T-boxes were then demonstrated to regulate genes encoding amino acid biosynthetic enzymes and transporters (Henkin 1994; Pelchat and Lapointe 1999; Sarsero et al. 2000), both in B. subtilis and other Firmicutes (Grundy and Henkin 1994; Grundy et al. 1997a; van de Guchte et al. 1998; Delorme et al. 1999; Panina et al. 2003). An important role in these studies was played by the comparative genomics approaches, since the relatively large size and high level of sequence and structural similarity of T-boxes made possible highly reliable predictions (Henkin et al. 1992; Putzer et al. 1992; Grundy and Henkin 1994; Chopin et al. 1998; Delorme et al. 1999; Grundy et al. 2002a; Mwangi and Siggia 2003; Panina et al. 2003; Rodionov et al. 2004; Gutierrez-Preciado et al. 2005). In particular, these studies demonstrated that T-boxes may regulate not only premature termination of transcription, but initiation of translation, since in the Actinobacteria, Tbox alternative structures overlap with the Shine-Dalgarno boxes (Fig. 1C; Seliverstov et al. 2005).

Using a sample of known T-boxes, we constructed a search pattern and used it to scan available bacterial genomes. We predicted the specificity of amino acid transporters analyzing the specifier codons in T-boxes that regulate genes encoding these transporters and use other methods of comparative genomics to obtain additional, independent evidence. The regulation by $\mathrm{T}$-boxes seems to be rather flexible and labile: in some cases, only a few genes in a set of orthologs are regulated by this mechanism. This may be caused by the diversity of systems regulating amino acid biosynthesis (Gutierrez-Preciado et al. 2005; Panina et al. 2003; Rodionov et al. 2004). In particular, we observed several cases of T-box regulon expansion caused by apparent loss of other regulatory systems. T-box sequences are sufficiently long to construct phylogenetic trees, although of course the order of deep branching events cannot be resolved. Still, analysis of reliable terminal branches revealed a number of interesting features, in particular, T-box duplications both in situ and accompanied by moving to another region, as well as changes in specificity. Finally, we described a new class of T-boxes, where a single specifier hairpin is followed by two repeated antiterminator/terminator structures (Fig. 3), and an unusual form of reduced T-boxes in the Actinobacteria (Fig. 1D).

\section{RESULTS}

\section{T-box regulons}

Initial scanning using the RNA-pattern program identified 805 T-boxes in 96 bacterial genomes. T-boxes were widely distributed in Gram-positive bacteria, mainly in the Firmicutes, but also in the Actinobacteria. Moreover, T-boxes were found in some Gram-negative bacteria ( $\delta$-proteobacteria) and other groups (Deinococcales/Thermales, Chloroflexi, Dictyoglomi). The specifier codon was clearly identifiable in 765 T-boxes (95\%).

Preliminary functional annotation of T-box-regulated genes (including parts of candidate operons) was done by similarity search. Genes regulated by T-boxes (Supplemental Table S1) encode aminoacyl-tRNA synthetases, biosynthetic enzymes (Table 1), and amino acid transporters (Table 2). T-boxes responding to 19 amino acids (excluding glutamate) were identified. Functional and taxonomic distribution of T-boxes varied between amino acids. For example, only one GLN-T-box was observed, upstream of the gltX gene in Clostridium perfringens.

\section{Aminoacyl-tRNA synthetases}

In most Firmicutes, T-boxes regulate aminoacyl-tRNA synthetases for aromatic and branched-chain amino acids, serine, asparagine, aspartate, and glycine. The least diverse taxonomic distribution was observed for T-boxes regulating prolyl- and lysyl-tRNA synthetases. On the other hand, in the Bacillales, T-boxes regulate aminoacyl-tRNA synthetases for most amino acids. Relatively fewer T-boxes regulating aminoacyl-tRNA synthetases were observed in Streptococcus spp. Outside Firmicutes, T-boxes regulate some aminoacyl-tRNA synthetases in the Actinobacteria (isoleucine), Atopobium minutum (phenylalanine), Deinococcales/Thermales (isoleucine, valine, glycine), Chloroflexi (isoleucine, leucine), Dictyoglomi (threonine), and Thermomicrobium roseum.

The specificity of T-boxes suggested by the specifier codon is largely consistent with the functional specificity of regulated aminoacyl-tRNA synthetases predicted from homology. One case where the T-box specificity is different from the annotated aminoacyl-tRNA synthetase specificity is the metS2 gene of Clostridium beijerinckii. The initial reason for the functional annotation of this gene, present in the Clostridiales as the methyonyl-tRNA synthetase, probably was weak similarity ( $17 \%$ identity) to met $G$ of 

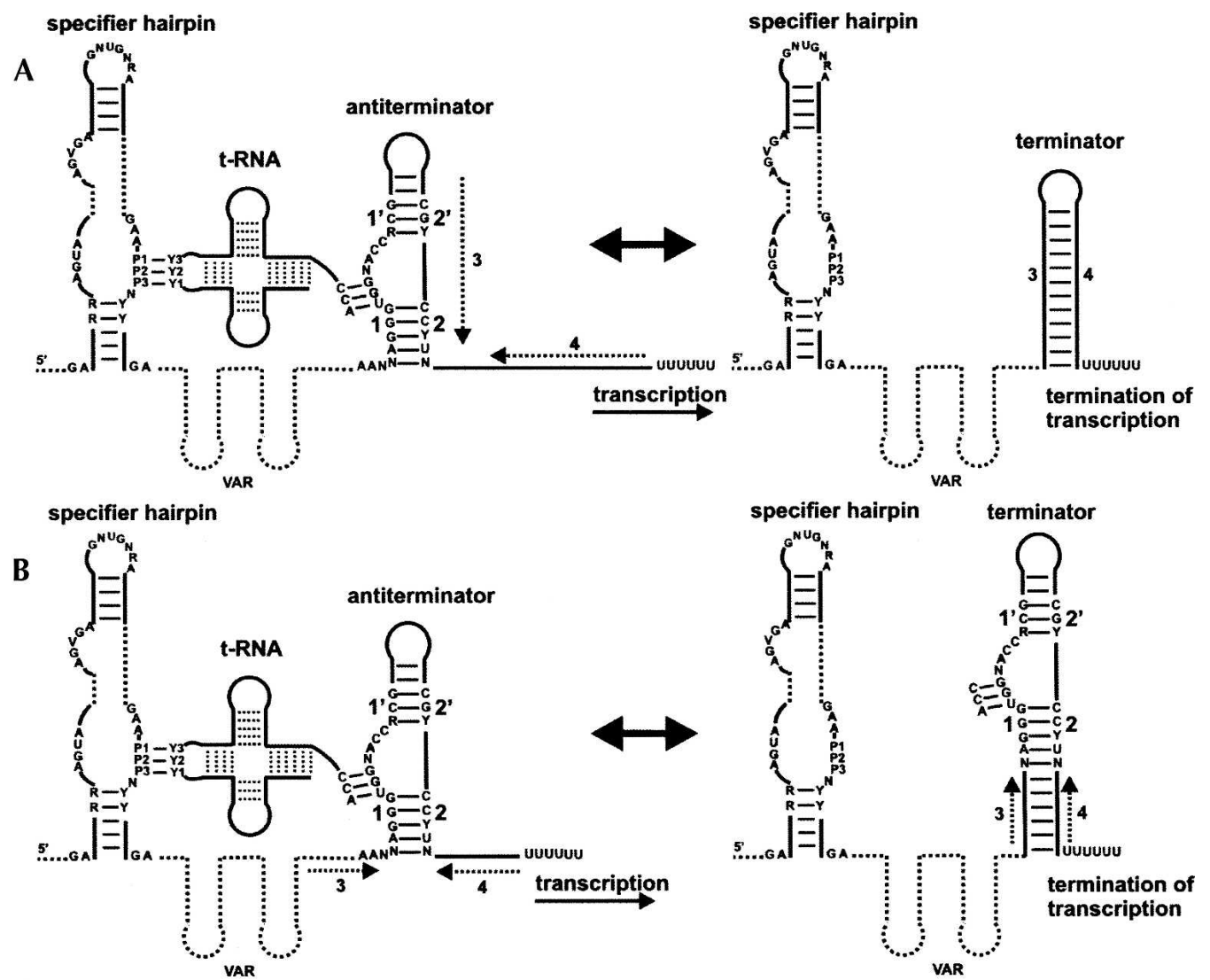

C

specifier hairpin
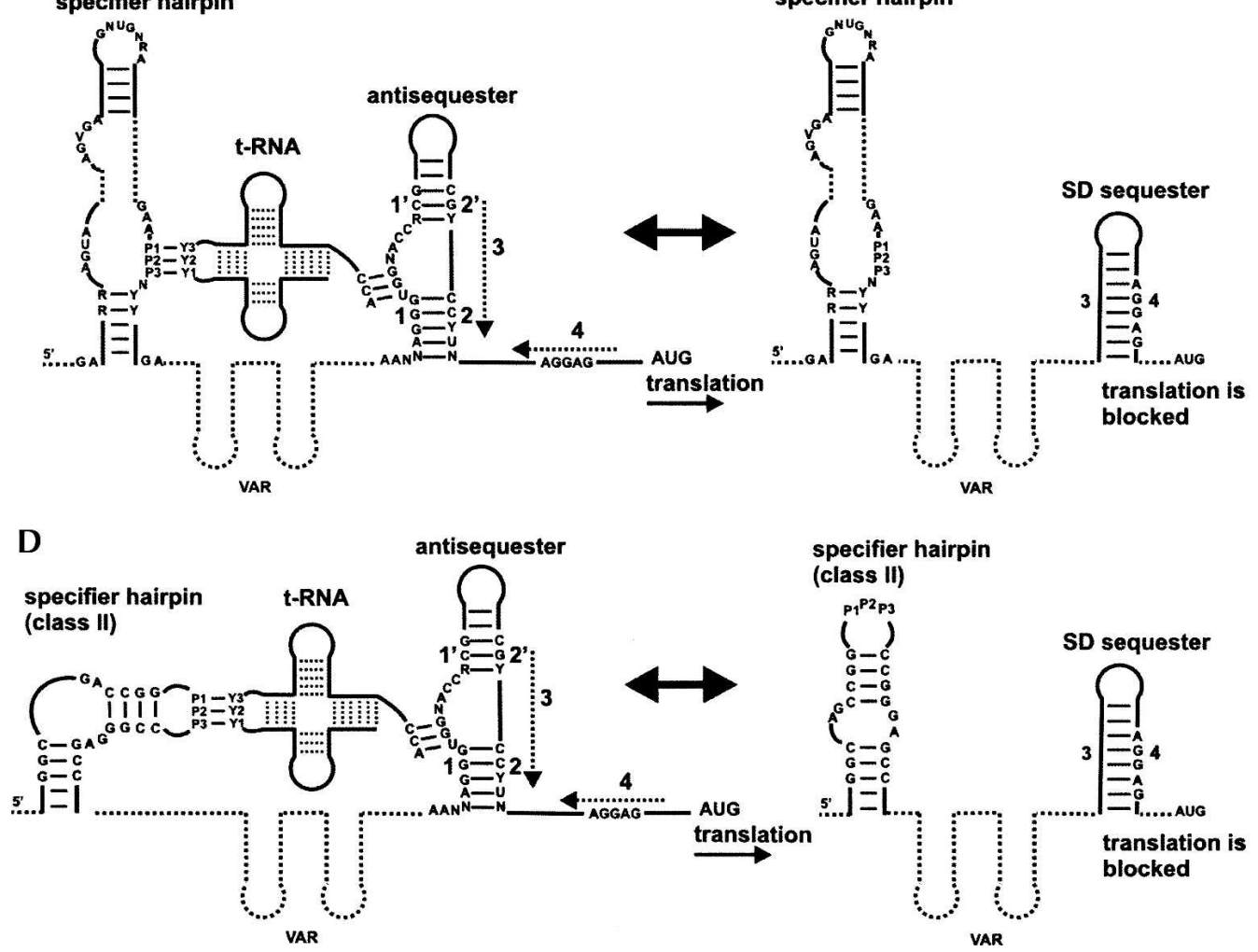

FIGURE 1. T-box regulation mechanism. $(A, B)$ Transcription antitermination; $(C, D)$ regulation of translation initiation. $(D)$ The noncanonical variant of T-boxes in the Actinobacteria. The T-box structure contains (solid line) conserved base-paired regions and (VAR, dotted line) variable or facultative ones. The alternative antiterminator/antisequestor and terminator/sequestor stems are numbered $1\left(1^{\prime}\right)-2\left(2^{\prime}\right)$ and $3-4$, respectively. (P1-P2-P3) The T-box specifier codon; (Y1-Y2-Y3) the tRNA anticodon; (AGGAG) the ribosome-binding site. 
TABLE 1. Regulation of aminoacyl-tRNA synthetases and amino acid biosynthetic genes by T-box antitermination in bacteria

\begin{tabular}{|c|c|}
\hline T-box specificity & Phylogenetic distribution of T-boxes \\
\hline \multicolumn{2}{|l|}{ Aminoacyl-tRNA synthetases } \\
\hline Aromatic amino acids & Most Firmicutes, Atopobium minutum \\
\hline Branched-chain amino acids & $\begin{array}{l}\text { Most Firmicutes, Actinobacteria (ileS), Deinococcales/Thermales (ileS, valS), Chloroflexi (ileS), } \\
\text { Thermomicrobium roseum (leuS) }\end{array}$ \\
\hline Methionine & Bacillales, Clostridiales, Thermoanaerobacter tengcongensis \\
\hline Proline & Some Bacillales, Clostridiales \\
\hline Cysteine & Bacillales, some Lactobacillales, Clostridiales, Thermoanaerobacteriales \\
\hline Histidine & Bacillales, Lactobacillales (except Streptococcus spp.), some Clostridiales, T. tengcongensis \\
\hline Arginine & Bacillales, Lactobacillales (except Streptococcus spp.), Clostridiales \\
\hline Threonine & Bacillales, Lactobacillales, Clostridiales, Dictyoglomi, T. roseum \\
\hline Serine & Most Firmicutes \\
\hline Alanine & Bacillales, Lactobacillales, Clostridiales \\
\hline Asparagine and aspartate & Most Firmicutes (except Streptococcus spp., Mycoplasmatales, Entomoplasmatales) \\
\hline Glycine & Most Firmicutes, Deinococcales/Thermales \\
\hline Lysine & Bacillus cereus, Clostridium thermocellum \\
\hline \multicolumn{2}{|l|}{ Amino acid biosynthetic genes } \\
\hline Aromatic amino acds & Most Firmicutes, Chloroflexi and Dictyoglomi (trp operon); some Firmicutes (aro genes, pheA, pah) \\
\hline Branched-chain amino acids & Bacillales, Clostridiales, Syntrophomonas wolfei, $\delta$-proteobacteria (leu), Dictyoglomi, T. roseum \\
\hline Methionine & Lactobacillales (except Streptococcus spp.), Desulfotomaculum reducens \\
\hline Proline & Bacillales, Desulfitobacterium hafniense, D. reducens \\
\hline Cysteine & Bacillales, Enterococcus faecalis, Clostridium acetobutylicum, Dictyoglomi \\
\hline Histidine & Some Lactobacillales \\
\hline Arginine & Clostridium difficile \\
\hline Threonine & B. cereus, C. difficile \\
\hline Serine & Some Firmicutes \\
\hline Alanine & - \\
\hline Asparagine and aspartate & Some Firmicutes \\
\hline Glutamine & Clostridium perfringes \\
\hline Glycine & - \\
\hline Lysine & - \\
\hline
\end{tabular}

The T-box specificity and phylogenetic distribution of T-boxes are shown in the first and the second column, respectively.

Escherichia coli (metS2 does not show significant similarity to metS from B. subtilis). However, in C. beijerinckii, this gene is preceded by a LYS-T-box, which is also most similar to other LYS-T-boxes. This suggests that metS2 may be a lysyl-tRNA synthetase (see Discussion).

\section{Amino acid metabolism}

T-box regulation of amino acid biosynthetic operons is rather uneven (Table 1). The trp and his operons and the asn $A$ genes are regulated by $\mathrm{T}$-boxes in most families of the Firmicutes, but not in all representatives of these families (trp being more, his and asnA less frequent). Branchedchain and cysteine biosynthetic operons are regulated by T-boxes in most Bacillales and Clostridiales. MET-T-boxes regulating methionine biosynthesis genes are restricted to the Lactobacillaceae. T-box regulation of serine and proline biosynthesis genes is restricted to the Firmicutes and rather rare. At that, PRO-T-boxes upstream of the biosynthetic pro genes clearly form a branch distinct from prolyl-tRNA synthetase PRO-T-boxes.

In some cases, T-box regulation of biosynthetic genes is restricted to one or two genomes. Thus, the arg genes are regulated by ARG-T-boxes only in Clostridium difficile, whereas the hom and thrCB genes involved in threonine biosynthesis are regulated by THR-T-boxes in C. difficile and Bacillus cereus (see the section on the evolution of T-box regulation).

T-boxes also regulate the aro genes (common pathway of aromatic amino acid biosynthesis), pah (phenylalanine-totyrosine conversion), pheA (phenylalanine/tyrosine biosynthesis), $u b i G, y r h B, y r h A$ (reverse synthesis of cysteine from methionine), and phenylacetate-coenzyme A ligase (phenylalanine catabolism, in the incomplete genome of Desulfotomaculum reducens).

Outside the Firmicutes, T-box regulation of biosynthetic operons is rare: the leu operons in $\delta$-proteobacteria, the cysE gene and the leu operon in Dictyoglomus thermophilum, the leu operon in T. roseum (Chloroflexi), and the trp operon in the Chloroflexi and D. thermophilum. Notably, operons regulated by $\mathrm{T}$-boxes in these taxonomy groups are also most frequently regulated by T-boxes in the Firmicutes. It looks like there is a tendency of certain amino acid biosynthesis pathways to be regulated by T-boxes.

In several cases, T-boxes were observed upstream of genes whose involvement in amino acid metabolism is not straightforward (Table 3 ). The $m d h$ gene (putative metal-dependent hydrolase) or the met operon including this gene is 
TABLE 2. Regulation of amino acid transporters by T-box antitermination in bacteria

\begin{tabular}{|c|c|c|c|c|}
\hline Gene & $\begin{array}{l}\text { T-box } \\
\text { specificity }\end{array}$ & Predicted function & Bacteria & $\mathrm{P} / \mathrm{C}$ \\
\hline ycbK (COG0697) & TRP & $\begin{array}{l}\text { Putative efflux protein (Valbuzzi } \\
\text { and Yanofsky 2001) }\end{array}$ & Bacillus subtilis, Bacillus licheniformis & \\
\hline yhaG & TRP & $\begin{array}{l}\text { Tryptophan transporter (Gutierrez- } \\
\text { Preciado et al. 2005) }\end{array}$ & Clostridiales & \\
\hline \multicolumn{5}{|c|}{ 2.A.3 The amino acid-polyamine-organocation (APC) superfamily } \\
\hline yvbW (COG1113) & LEU & Leucine-specific permease & B. subtilis, B. licheniformis & $\mathrm{P}$ \\
\hline ykbA (steT) (COG0531) & THR & $\begin{array}{l}\text { Threonine-specific permease } \\
\text { (Reig et al. 2007) }\end{array}$ & Bacillus cereus & $\mathrm{P}$ \\
\hline \multicolumn{5}{|c|}{ 2.A.1 MFS superfamily (the major facilitator superfamily) } \\
\hline lys $X^{*}(\mathrm{COG} 0477)$ & LYS & Lysine transporter & Some Bacillales & $\mathrm{P}$ \\
\hline $\arg X^{*}(\mathrm{COG} 1457)$ & ARG & Arginine permease & Clostridium difficile (CD1716) & $\mathrm{P}$ \\
\hline leuX* (COG1139) & LEU & Leucine transporter & $\begin{array}{l}\text { Desulfotomaculum reducens } \\
\text { (Dred_0433) }\end{array}$ & $P$ \\
\hline \multicolumn{5}{|c|}{ 2.A.23 DAACS transporter family (the dicarboxylate/amino acid:cation $\left[\mathrm{Na}^{+}\right.$or $\left.\mathrm{H}^{+}\right]$symporters) } \\
\hline cysP1* (COG1823) & CYS & Cysteine transporter & $\begin{array}{l}\text { Clostridium perfringens (CPE0947, } \\
\text { CPE0967), Clostridium botulinum }\end{array}$ & $\mathrm{P}$ \\
\hline \multicolumn{5}{|l|}{ cysP2* (COG1301) } \\
\hline \multicolumn{5}{|l|}{ 2.A.35 The $\mathrm{NhaC} \mathrm{Na}^{+}: \mathrm{H}^{+}$antiporter ( $\left.\mathrm{NhaC}\right)$ family } \\
\hline \multicolumn{5}{|c|}{ 2.A.26 The branched-chain amino acid:cation symporter family } \\
\hline \multirow[t]{3}{*}{ brnQ/braB (COG1114) (Tauch et al. 1998) } & ILE & $\begin{array}{l}\text { Branched-chain amino acid } \\
\text { carrier protein }\end{array}$ & $\begin{array}{l}\text { Some Bacillales, Lactobacillales, } \\
\text { and Clostridiales }\end{array}$ & $P$ \\
\hline & THR & & B. cereus, Clostridium tetani & $\mathrm{P}$ \\
\hline & VAL & & Some Lactobacillales & $P$ \\
\hline \multicolumn{5}{|l|}{ 3.A.1 The ATP-binding cassette (ABC) superfamily } \\
\hline metNPQ (COG1135, COG2011, COG1464) & MET & $\begin{array}{l}\text { Methionine ABC transporter } \\
\text { (Zhang et al. 2003; Hullo } \\
\text { et al. 2004) }\end{array}$ & $\begin{array}{l}\text { Lactobacillales, Enterococcus } \\
\text { faecalis }\end{array}$ & \\
\hline yqiXYZ (COG0834, COG765, COG1126) & ARG & Arginine $\mathrm{ABC}$ transporter & C. difficile $(C D 0750,51,52)$ & $\mathrm{P}$ \\
\hline hisXYZ* (COG0765, COG1126, COG0834) & HIS & Histidine $A B C$ transporter & $\begin{array}{l}\text { Lactobacillales, C. difficile } \\
\quad(C D 1774,75,76) \text {, L. monocytogenes } \\
\quad(\text { Imo1740,39,38), E. faecalis }\end{array}$ & $P$ \\
\hline \multirow[t]{2}{*}{ yckKJI (COG0834, COG765, COG1126) } & CYS & $\begin{array}{l}\text { Cysteine ABC transporter } \\
\text { (Burguiere et al. 2004) }\end{array}$ & $\begin{array}{l}\text { Clostridium acetobutylicum } \\
\quad(\text { CAC3325, 26, 27), Lactobacillales }\end{array}$ & $P$ \\
\hline & MET & & & \\
\hline $\begin{array}{l}\text { ytmKLMN (COG0834, COG0765, } \\
\text { COG1464) }\end{array}$ & MET & $\begin{array}{l}\text { Cysteine ABC transporter } \\
\text { (Burguiere et al. 2004) }\end{array}$ & $\begin{array}{l}\text { Leuconostoc mesenteroides } \\
(\text { LEUM_0136, 37, 38, 39) }\end{array}$ & $\mathrm{P}$ \\
\hline $\begin{array}{l}\text { aspQHMP (COG0834, COG1126, } \\
\text { COG0765) }\end{array}$ & ASP & $\mathrm{ASP} \backslash \mathrm{ASN} A \mathrm{ABC}$ transporter & $\begin{array}{l}\text { Lactobacillus johnsonii } \\
\quad(\text { LJO752, 53, 54, 55) }\end{array}$ & $P$ \\
\hline $\operatorname{trpXYZ*}(C O G 2984$, COG0559, COG1101) & TRP & Tryptophan ABC transporter & $\begin{array}{l}\text { Peptococcaceae, Streptococcus } \\
\text { spp. (e.g., SPD_0954, 55, 56), } \\
\text { P. larvae }\end{array}$ & $\mathrm{P}$ \\
\hline $\boldsymbol{m} \boldsymbol{t s} \boldsymbol{A B C}(-, \mathrm{COG} 1122, \mathrm{COG} 0619)$ & MET & Uptake of MET/or MET-precursors & $\begin{array}{l}\text { Some Lactobacillales } \\
\quad \text { (e.g., LEUM_1974, 73, 72) }\end{array}$ & $\mathrm{P}, \mathrm{C}$ \\
\hline \multirow[t]{6}{*}{ opp family (COG0747) } & TRP & Transporters of oligopeptides & $\begin{array}{l}\text { Some Lactobacillales } \\
\text { (e.g., Ip_0092), }\end{array}$ & $P$ \\
\hline & MET & & E. faecalis (EF3081) & $\mathrm{P}$ \\
\hline & ILE & & L. johnsonii (LJ1574) & $\mathrm{P}$ \\
\hline & LEU? & & Lactobacillus brevis (LVIS_0014) & - \\
\hline & LYS? & & Lactobacillus plantarum (Ip_3686) & - \\
\hline & $?$ & & Lactobacillus brevis LVIS_0024, 2175 & $?$ \\
\hline \multicolumn{5}{|c|}{ 2.A.22 The neurotransmitter:sodium symporter (NSS) family } \\
\hline \multirow[t]{4}{*}{ yocR/yhdH(COG0733) } & TRP & TRP sodium-dependent transporter & B. cereus $(B C 1430)$ & $\mathrm{P}$ \\
\hline & PHE & PHE sodium-dependent transporter & B. cereus (BC1767) & $\mathrm{P}$ \\
\hline & LEU & LEU sodium-dependent transporter & B. cereus $(B C 2170)$ & $\mathrm{P}$ \\
\hline & Met? & Sodium-dependent transporter & Clostridium tetani (CTC01948) & - \\
\hline \multicolumn{5}{|c|}{ 2.A.3 The amino acid-polyamine-organocation (APC) superfamily } \\
\hline ydgF \aapA (COG1113) & ? & ? & Lactobacillus reuteri & ? \\
\hline
\end{tabular}

All predicted transporters were divided into groups according to the classification from Saier et al. (2006). Newly identified candidate amino acid transporters are set in bold (genes named in this paper are marked by asterisks; COGs are shown in parentheses). The predicted specificities of T-boxes are indicated in the second column. The fifth column: (P) T-boxes regulating transporter genes that were shown to coevolve with T-boxes regulating corresponding biosynthetic/aminoacyl-tRNA synthetase genes (data not shown). (C) Genes were shown by positional analysis to be colocalized (co-regulated) with corresponding biosynthetic/aminoacyl-tRNA synthetase genes (Supplemental Table S1). 
TABLE 3. Regulation of enzymes by T-box antitermination in bacteria

\begin{tabular}{|c|c|c|c|c|}
\hline Gene & $\begin{array}{l}\text { T-box } \\
\text { specificity }\end{array}$ & Possible function & Bacteria & $\mathrm{P} / \mathrm{C}$ \\
\hline \multicolumn{5}{|c|}{ Putative aminotransferases (2.6.1.-) } \\
\hline $\begin{array}{l}\text { alaRT (yugGH)(COG1522, } \\
\text { COG0436) }\end{array}$ & ALA & $\begin{array}{l}\text { Putative alanine } \\
\text { transaminase(alaT) and } \\
\text { transcriptional regulator alaR }\end{array}$ & $\begin{array}{l}\text { Some Clostridiales, Peptococcaceae, } \\
\text { Moorella thermoacetica }\end{array}$ & \\
\hline yurG (COG0075) & SER & $\begin{array}{l}\text { Putative phosphoserine } \\
\text { aminotransferase }\end{array}$ & $\begin{array}{l}\text { Some Clostridiales, } \\
\text { Peptococcaceae, M. thermoacetica, }\end{array}$ & $\mathrm{C}$ \\
\hline Ip_2751 (COG1168) & MET & $\begin{array}{l}\text { Putative methionine } \\
\text { aminotransferase }\end{array}$ & Lactobacillus plantarum & $\mathrm{P}$ \\
\hline $\begin{array}{l}\text { OB1271-OB1272 } \\
\quad(\text { COG0454, COG1670) }\end{array}$ & LEU & $\begin{array}{l}\text { Putative } \\
\text { acetyltransferases }\end{array}$ & Oceanobacillus iheyensis & $\mathrm{P}$ \\
\hline \multicolumn{5}{|l|}{ Hypothetical proteins } \\
\hline yxjl (Bacillus subtilis) & ALA & $\begin{array}{l}\text { Conserved hypothetical } \\
\text { protein }\end{array}$ & Streptococcaecae & $\mathrm{C}$ \\
\hline Imo2587 (COG9112) & TRP & $\begin{array}{l}\text { Conserved hypothetical } \\
\text { protein }\end{array}$ & Listeria monocytogenes & $\mathrm{P}$ \\
\hline $068 \_0017$ & TYR & $\begin{array}{l}\text { Conserved hypothetical } \\
\text { protein }\end{array}$ & Ruminococcus albus & $\mathrm{P}$ \\
\hline 079_0081 & GLU & Conserved hypothetical protein & Clostridium beijerinckii (cbei_2130) & $\mathrm{P}$ \\
\hline \multicolumn{5}{|l|}{ Other genes } \\
\hline Ip_3666 (COG0179) & ILE & $\begin{array}{l}\text { 2-Hydroxypenta-2,4- } \\
\text { dienoate hydratase }\end{array}$ & $\begin{array}{l}\text { Some Lactobacillales } \\
\text { [e.g., L. plantarum (Ip_3666)] }\end{array}$ & $\mathrm{P}$ \\
\hline Cthe_0234 (COG0318) & LEU & $\begin{array}{l}\text { AMP-dependent } \\
\text { synthetase and ligase }\end{array}$ & Clostridium thermocellum & $\mathrm{P}$ \\
\hline panE1 (COG1893) & MET? & 2-Dehydropantoate & L. reuteri, L. plantarum (panE1) & C \\
\hline panE2 (COG1893) & ILE & 2-reductase & L. reuteri, L. plantarum (panE2) & $\mathrm{P}$ \\
\hline Swol_2237 (COG1014) & LEU & Putative oxidoreductase & Syntrophomonas wolfei & $P$ \\
\hline yngl (COG0318) & THR? & $\begin{array}{l}\text { Fatty-acid-CoA } \\
\quad \text { ligase } \backslash \text { acyl-CoA synthase }\end{array}$ & Heliobacillus mobilis & - \\
\hline yngl (COG1541) & PHE & $\begin{array}{l}\text { Phenylacetate-coenzyme } \\
\text { A ligase }\end{array}$ & D. reducens (Dred_2884) & $\mathrm{P}$ \\
\hline LEUM_0134 LEUM_0135 & MET & $\begin{array}{l}\text { Putative uroporphyrinogen-III } \\
\text { decarboxylase }\end{array}$ & Leuconostoc mesenteroides & $\mathrm{P}$ \\
\hline mdh (COG1878) & MET & Metal-dependent hydrolase & $\begin{array}{l}\text { S. aureus (SAV0355), } \\
\text { L. mesenteroides (LEUM_0115) }\end{array}$ & $\mathrm{P}, \mathrm{C}$ \\
\hline 114_o008 (COG1619) & LEU & Microcin C7 resistance protein & Ruminococcus albus & $\mathrm{C}$ \\
\hline 114_0009 & & Conserved hypothetical protein & & \\
\hline
\end{tabular}

Newly identified regulon members are set in bold; COGs are shown in parentheses. The fifth column is as in Table 2.

preceded by MET-T-boxes in Leuconostoc mesenteroides and Staphylococcus aureus, respectively. Notably, in the Streptococcaceae, $m d h$ also has been predicted to be coregulated with methionine biosynthesis genes by a transcription factor (Rodionov et al. 2004). The role of the $m d h$ gene product in the methionine metabolism is not clear. Even less clear cases are SMU.932 (putative uroporphyrinogen-III decarboxylase) preceded by a MET-T-box in $L$. mesenteroides; lp_3666 (annotated as 2-oxo-hept-3-ene-1,7dioate hydratase/2-oxo-hept-4-ene-1,7-dioate hydratase) preceded by a ILE-T-box in some Lactobacillaceae (Lactobacillus reuteri [two regulated paralogs]; Lactobacillus plantarum, Oenococcus oeni); the pantothenate biosynthesis gene panE encoding 2-dehydropantoate 2-reductase preceded by a ILE-T-box in $L$. reuteri and L. plantarum; a Phe-T-boxregulated phenylacetate-coenzymeA-ligase in the unfinished genome of $D$. reducens; and the $y n g I$ gene annotated as fatty-acid-CoA ligase/acyl-CoA synthase and preceded by a T-box with unclear specificity (possibly a threonine one) in Heliobacillus mobilis. Finally, the incomplete genome of Ruminococcus albus has a LEU-T-box upstream of a candidate three-gene operon encoding a microcin C7 resistance protein, a conserved hypothetical protein and 2-isopropylmalate synthase (leuA, leucine biosynthesis) (Table 3).

Genes encoding enzymes from common pathways may be regulated by different T-boxes in different genomes. For instance, the aro genes encoding enzymes from the common part of the aromatic amino acid synthesis pathway are regulated by TYR-T-boxes in $B$. cereus, by PHE-T-boxes in the Peptococcaceae, H. mobilis, Moorella thermoacetica, Clostridium thermocellum, and by TRP-T-boxes in the Chlorophlexales.

Similarly, in the Bacillales, the branched-chain amino acid operon ilv may be preceded by a LEU-T-box (in most 
Bacillus species: B. subtilis, Bacillus licheniformis, Bacillus halodurans, Bacillus stearothermophilus, Bacillus clausii) or by a ILE-T-box (B. cereus, Oceanobacillus iheyensis). In the Clostridiales, the ilv genes are regulated mainly by LEU-Tboxes, although the separate gene ilvC in Clostridium acetobutylicum is regulated by a VAL-T-box. The most interesting case was observed in D. reducens, where the ilv operon is preceded by a tandem formed by recently duplicated ILE- and LEU-T-boxes; the ILE-T-box is the original one (see the section on the evolution of T-box regulation).

Aminotransferases (EC 2.6.1.-) seem to be a functional group of enzymes most often regulated by T-boxes. METT-boxes were found upstream of the operon $y k r U V$-panE from $L$. reuteri; in B. subtilis, the orthologous aminotransferase $\mathrm{YkrV}(\mathrm{MtnE})$ catalyzes the final step of a long methionine salvage pathway (recycling of $5^{\prime}$-methylthioadenosine to methionine) (Sekowska and Danchin 2002). Another, nonhomologous putative aminotransferase lp_2751 is preceded by a MET-T-box in L. plantarum. Putative phosphoserine aminotransferase $y u r G$, nonhomologous to the classical gene $\operatorname{ser} C$, is colocalized with $\operatorname{ser} A$ and regulated by a SER-T-box in the Clostridiales, Syntrophomonas wolfei, and M. thermoacetica. Putative alanine transaminase yugH/alaT forms a candidate operon with a transcriptional regulator alaR (the Subtilist database, http://genolist.pasteur.fr/SubtiList/, A.L. Sonenshein, pers. com.) and in addition is preceded by an ALA-T-box in the Clostridiales, the Peptococcaceae, and M. thermoacetica. Finally, in O. iheyensis, a LYS-T-box is found upstream of the OB1271-OB1272 genes encoding possible acetyltransferases from the GNAT family.

\section{Transporters}

Identification of a T-box with a recognizable specifier codon upstream of a candidate transporter gene is a strong indicator to the transporter specificity toward an amino acid or maybe its precursor. We observed a large number of known and new amino acid transporters likely regulated by T-boxes (Table 2). They represent several superfamilies of both secondary transporters and $\mathrm{ABC}$ transporters and are involved in transport of three branched-chain amino acids, threonine, lysine, histidine, arginine, cysteine, methionine, three aromatic amino acids, aspartate, or their precursors.

In several cases, closely related, likely orthologous transporters are regulated by different $\mathrm{T}$-boxes in different genomes. This may represent either changes in transporter specificity or, more likely, nonselective transport of several related amino acids. The examples of this type are the transporters of branched-chain amino acids $\mathrm{brnA} / \mathrm{braB}$ regulated by ILE-T-boxes, THR-T-boxes, or VAL-T-boxes in various Firmicutes and the $y o c R / y h d H$ transporters from the NSS superfamily preceded by TRP-, PHE-, and LEU-Tboxes in B. cereus and possible MET-T-boxes in Clostridium tetani. Probably the most diverse regulation was observed for the $O P P$ ABC-transporters involved in oligopeptide transport (TC 3.A.1.5._): representatives of this family are regulated by TRP-, MET-, ILE-, and also possibly LEU- and LYS-T-boxes, mainly in the Lactobacillus spp. The latter observation is not surprising, given that these bacteria live in protein-rich media.

ABC-type transporters $y c k K J I$ and $y$ tmKLMN have been shown experimentally to mediate L-cysteine uptake in B. subtilis (Burguiere et al. 2004). Interestingly, in B. subtilis, yckKJI is regulated by a CYS-T-box, whereas both $y c k K J I$ and $y t m K L M N$ are regulated by MET-T-boxes in C. acetobutylicum and some Lactobacillales, respectively. Cysteine may be synthesized via cysteine recycling, whereas methionine is synthesized from homoserine and cysteine. Thus, candidate cysteine transporters seem to be regulated by two different amino acids, cysteine and methionine, which are close on the metabolic map, although one cannot definitely rule out changes in the transporter specificity.

\section{Evolution of T-box regulation}

\section{Regulatory mechanisms}

In most cases, T-boxes regulate premature termination of transcription (Fig. 1A). The T-box-containing hairpin, stabilized by interaction with an uncharged tRNA, is an antiterminator, alternative to an intrinsic transcriptional terminator of transcription (a hairpin followed by a run of uridines). Transcriptional terminators alternative to T-box hairpins were observed in most T-boxes of the Firmicutes as well as $\delta$-proteobacteria, Deinococcales/ Thermales, and Chloroflexi, Dictyoglomi. However, some T-boxes have a different mechanism of the terminator formation. The terminator of the S. aureus ileS T-box has been shown to contain an additional region capable of base-pairing that extends the antiterminator structure (Fig. 1B; Grundy et al. 1997a). In this case, T-box-tRNA interaction would be expected to prevent the base-pairing extending the antiterminator rather than promoting formation of an alternative structure. Such unusual Tboxes were observed in some bacteria: Streptococcaecae, Lactobacillaceae, Leuconostocaceae (ALA-T-box, alaS), Clostridiaceae (GLY-T-box, $g l y S$ ), Streptococcaecae (SERT-box, serS), and S. aureus (ILE-T-box, ileS) (data not shown).

However, this is not the only possibility, as the T-boxcontaining hairpin may be alternative to a hairpin that masks the Shine-Dalgarno box and thus interferes with the initiation of translation (Fig. 1C, sequester hairpin; Seliverstov et al. 2005). Such T-boxes were found upstream of the ileS genes in some Actinobacteria (all Actinomycetales and Bifidobacterium longum). In the latter case, the sequester hairpin is located $\sim 100$ nucleotides (nt) downstream from the T-box hairpin, and a complicated 
rearrangement of alternative hairpins is predicted to lead to sequestering of the Shine-Dalgarno box (data not shown).

Notably, the translation-regulating T-boxes of the classical type were observed only in Thermobifida fusca and the Streptomyces spp. In other actinobacterial species, a new variant of the specifier hairpin was observed (Fig. 1D). It is much shorter and the specifier codon is located in the loop of the hairpin, and not in the bulge, as in the classic T-box structure. The predicted structure is supported by several cases of compensatory substitutions retaining base-pairing (Fig. 2).

This is consistent with the observation that in Actinobacteria (Actinomycetales), other RNA regulatory elements, such as riboswitches, tend to regulate initiation of translation and sometimes represent reduced versions of the riboswitches found in other species (Vitreschak et al. 2004). On the other hand, in some other actinobacteria, Rubrobacter xylanophilus (Rubrobacterales, regulation of ileS), A. minutum (Coriobacteriales, regulation of pheST), the transcription antitermination mechanism was predicted.

\section{Double and partially double T-boxes}

In some cases, T-boxes are arranged in tandem (Table 4). Predominantly this happens upstream of biosynthetic and transport genes, as it has been previously described for the trp operon (Panina et al. 2003; Gutierrez-Preciado et al. 2005). The two major types of such tandems are double Tboxes, that is, repeats of complete T-box structures (Fig. 3A), and partially double T-boxes, formed by a single specifier hairpin followed by two repeated terminator/antiterminator structures closely located to each other (Fig. 3B).

In most cases, formation of double T-boxes is due to recent duplications, so that the $\mathrm{T}$-boxes forming such pairs are the closest relatives and have the same specificity (Table 4). An interesting exception is the tandem of ILE- and LEU-T-boxes upstream of the ilv operon in D. reducens; the enzymes encoded by this operon form the common biosynthetic pathway of isoleucine, leucine, and valine. The phylogenetic analysis demonstrates that the original T-box had ILE specificity (see below about changes of T-box specificity). In most cases, the tandem T-box duplications

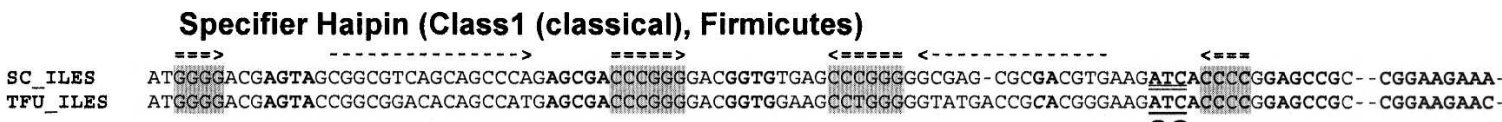
TFU_ILES ATGGGGACGAGTACCGGCGGACACAGCCATGAGCGACCCGGGGACGGTGGAAGCCTGGGGGTATGACCGCACGGGAAGATCACC
AGTA-box

MT_ILES
NOC_ILES
AN_ILES
BL_ILES
PAC_ILES
CD_ILES
CJ_ILES
AUU_ILES
LX_ILES
RH_ILES
KR_ILES
CM_ILES
BLO_ILES

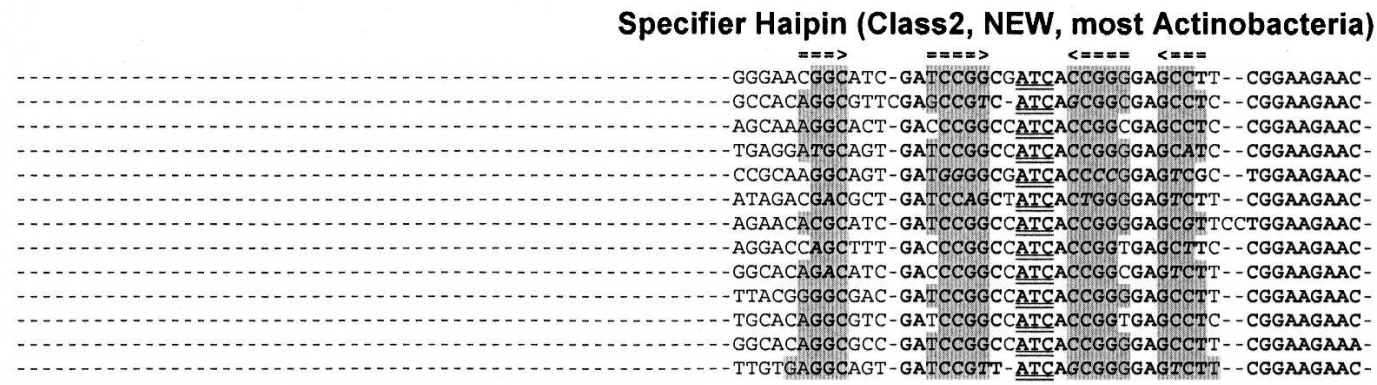

SC_ILES
TFU_ILES
MT_ILES
NOC_ILES
AN_ILES
BL_ILES
PAC_ILES
CD_ILES
CJ_ILES
AUU_ILES
LX_ILES
RH_ILES
KR_ILES
CM_ILES
BLO_ILES

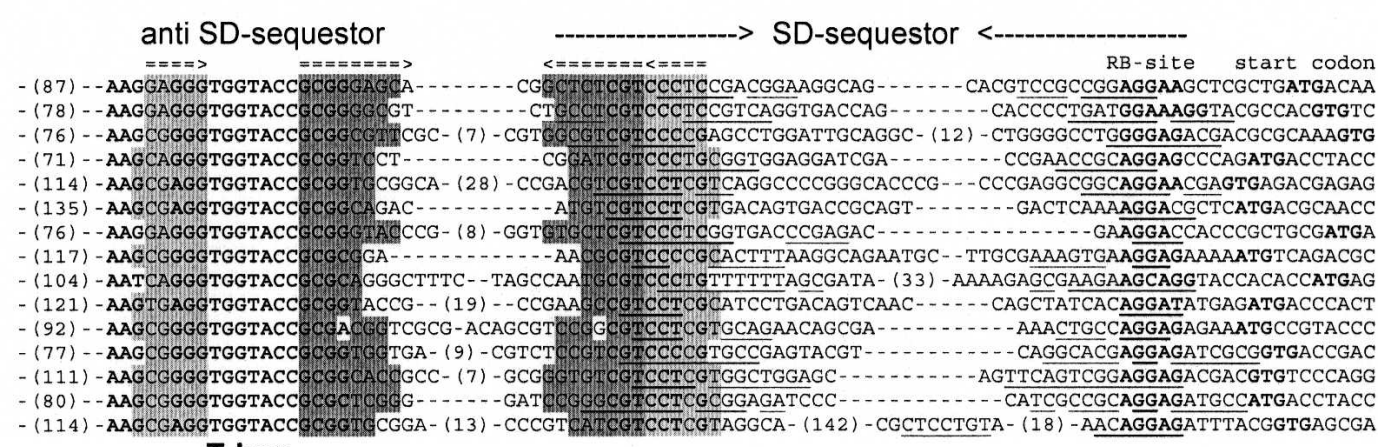

T-box

FIGURE 2. Alignment of the T-boxes regulating initiation of translation of the ileS gene in the Actinobacteria. (Top) Two different versions of the specifier hairpin region (the classical one as in Fig. 1C and the reduced one as in Fig. 1D). (Bottom) The sequestor/antisequestor region. Specifier codons (SC) are double-underlined. The complementary stems of the mRNA structure are shown by arrows above the alignment. (Gray) Basedpaired positions; (underline) the SD-sequester hairpin; (bold) conserved positions; (bold italic) non-consensus nucleotides; (light) non-conserved positions. The lengths of variable regions are given in brackets. (SC) Streptomyces spp.; (TFU) Thermobifida fusca; (MT) Mycobacterium spp.; (NOC) Nocardioides sp.; (AN) Actinomyces naeslundii; (BL) Brevibacterium linens; (PAC) Propionibacterium acnes; (CD, CJ) Corynebacterium spp.; (AAU) Arthrobacter aurescens; (LX) Leifsonia xyli; (RH) Rhodococcus str.; (KR) Kineococcus radiotolerans; (CM) Clavibacter michiganensis; (BLO) Bifidobacterium longum. 
TABLE 4. The distribution of tandem T-boxes in bacteria

\begin{tabular}{|c|c|c|c|}
\hline Regulated genes & $\begin{array}{l}\text { T-box } \\
\text { specificity }\end{array}$ & $\begin{array}{l}\text { Gene } \\
\text { function }\end{array}$ & Species \\
\hline \multicolumn{4}{|l|}{ Double T-boxes } \\
\hline trp operon & B & TRP-TRP & $\begin{array}{l}\text { Bacillales, C. beijerinckii, } \\
\text { D. hafniense }\end{array}$ \\
\hline pah & B & TYR-TYR & Bacillus cereus \\
\hline ilvEBCDA & B & ILE-ILE & B. cereus \\
\hline $\operatorname{aro} A$ & B & TYR-TYR & B. cereus \\
\hline hom & B & THR-THR & Clostridium difficile \\
\hline leuA & B & LEU-LEU & Clostridium thermocellum \\
\hline ilvDBNCB-leuACDBA & B & ILE-LEU & Desulfotomaculum reducens \\
\hline his $X Y Z$ & $\mathrm{~T}$ & HIS-HIS & Enterococcus faecalis \\
\hline thrZ & A & THR-THR & Bacillales \\
\hline \multicolumn{4}{|c|}{ Partially double T-boxes (two terminator-antiterminator structures) } \\
\hline trp operon & B & TRP & Thermoanaerobacter tengcongensis \\
\hline arolA-pheA & B & PHE & $\begin{array}{l}\text { Desulfotomaculum reducens, } \\
\text { Syntrophomonas wolfei }\end{array}$ \\
\hline serCA & B & SER & Desulfitobacterium hafniense \\
\hline his $X Y Z$ & $\mathrm{~T}$ & HIS & Lactobacillales \\
\hline $\operatorname{trpXY2}$ & $\mathrm{T}$ & PHE & D. reducens \\
\hline yhel & $\mathrm{T}$ & TYR & B. cereus \\
\hline yqiXYZ & $\mathrm{T}$ & ARG & C. difficile \\
\hline brnQ/braB2 & $\mathrm{T}$ & THR & Clostridium tetani \\
\hline yngl & $U$ & PHE & D. reducens \\
\hline \multicolumn{4}{|c|}{ Partially double T-boxes (three terminator-antiterminator structures) } \\
\hline yocR/yhdH2 & $\mathrm{T}$ & $\mathrm{PHE}$ & B. cereus \\
\hline
\end{tabular}

The regulated genes, the T-box specificity, gene function, and species are shown in the first, second, and third columns, respectively. Second column: (B) biosynthetic genes; (T) transporters; (A) aminoacyl-tRNA synthetases; (U) unknown.
The role of the partially double $\mathrm{T}$ boxes is much less clear. A straightforward modeling of RNA secondary structures leads to an absurd conclusion that such T-boxes will always form at least one terminator hairpin, and thus the genes would never be expressed. A trivial explanation that such T-boxes are not functional is refuted by the observation that they are conserved. In particular, the candidate histidine ABCtransporter his $X Y Z$ is regulated by partially double T-boxes in the Lactobacillaceae/Leuconostocaceae (L. plantarum, Lactobacillus sakei, L. reuteri, L. mesenteroides). Multiple alignment of the antiterminator/terminator regions (two for each genome) shows strong conservation of the RNA structures with some compensatory nucleotide substitutions (Fig. 4). In B. cereus, the yocR-yhdH2 operon is preceded by an even more complicated structure: the specifier hairpin followed by three adjacent antiterminator/terminator sites.

Whatever is their function, partially double T-boxes seem to evolve by duplication followed by deletion of the downstream specifier hairpin. A convincing example is provided by the are restricted to single lineages; the exceptions are the TRPT-boxes upstream of the trp operon in some Bacillales and also C. beijerinckii and Desulfitobacterium hafniense (cf. Gutierrez-Preciado et al. 2005, 2007) and THR-T-boxes upstream of the threonyl-tRNA synthetase gene thrZ, also in several Bacillales.

Again, such arrangements are similar to the ones observed in the analysis of riboswitches. The $5^{\prime}$ regulatory region of the $B$. clausii metE mRNA is formed by the S-box and B12 riboswitches (Sudarsan et al. 2006). Most glycine riboswitches possess two ligand-binding RNA domains that function cooperatively (Mandal et al. 2004). Recently, tandemly arranged THI (thiamin pyrophosphate) riboswitches were studied in detail (Sudarsan et al. 2006). Based on analogy with the riboswitches, one could expect that tandem arrangement of T-boxes would lead to a sharper (digital-like) response to uncharged tRNA concentrations. However, the glycine and THI riboswitches demonstrate different behavior: the ligand binding to the former is cooperative (Mandal et al. 2004), whereas the latter structures are bound independently (Welz and Breaker 2007). Thus the exact molecular mechanisms involved in the regulation by tandem T-boxes of the same or different specificity remain to be elucidated by experiment and by kinetic modeling of RNA structures.
ARG-T-box upstream of the candidate arginine ABC-transporter yqiXYZ from $C$. difficile. This T-box is a fairly recent result of a rapid genome-specific expansion (see below). The antiterminator/terminator sites $(\sim 60 \mathrm{nt})$ of this T-box are highly similar to each other ( $\sim 90 \%$ identity).

\section{Evolution of T-boxes}

In most cases, $\mathrm{T}$-boxes coevolve with the regulated genes by vertical descent. In such cases, the branches on the phylogenetic tree correspond well to the regulated operons, and the topology of the branches is consistent with the taxonomy. Such relationships may survive minor operon rearrangements: for example, yxjI was inserted upstream of the alaS gene in seven Streptococcus spp., forming the operon $y x j I$-alaS preceded by the ALA-T-box instead of the ancestral ALA-T-box-alaS locus (Fig. 5A). Similarly, genes were inserted between the VAL-T-box and the valS gene in most Streptococcus spp. T-boxes may be lost, for example, ASP-T-boxes upstream of the hisS-aspS in the Clostridiales; most CYS-T-boxes and MET-T-boxes upstream of the metS gene in the Lactobacillales; LEU-, ARG-, ASP-, and TYR-T-boxes upstream of the respective aminoacyl-tRNA synthetase genes in the Streptococcaeae, etc. (Supplemental Table S1). 


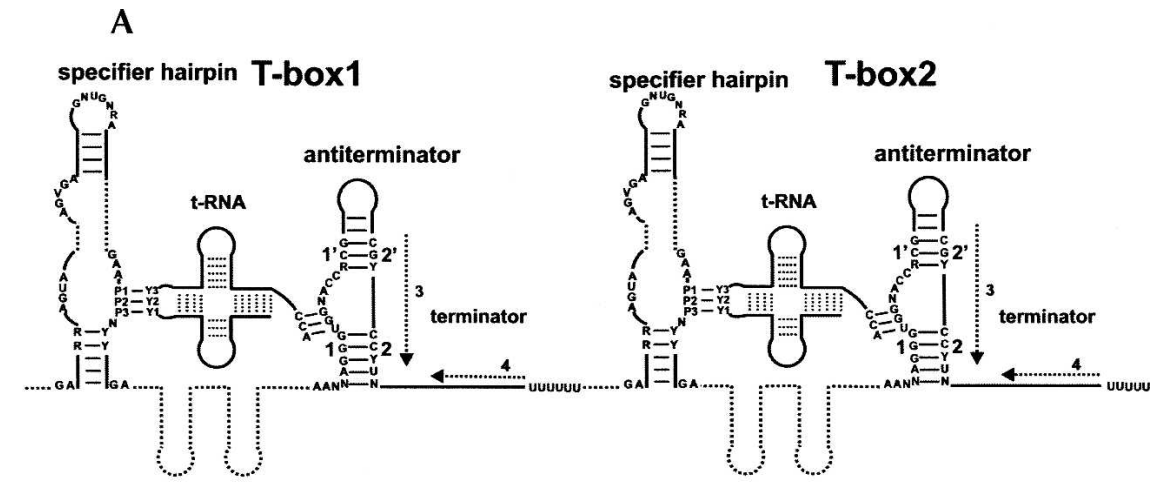

B

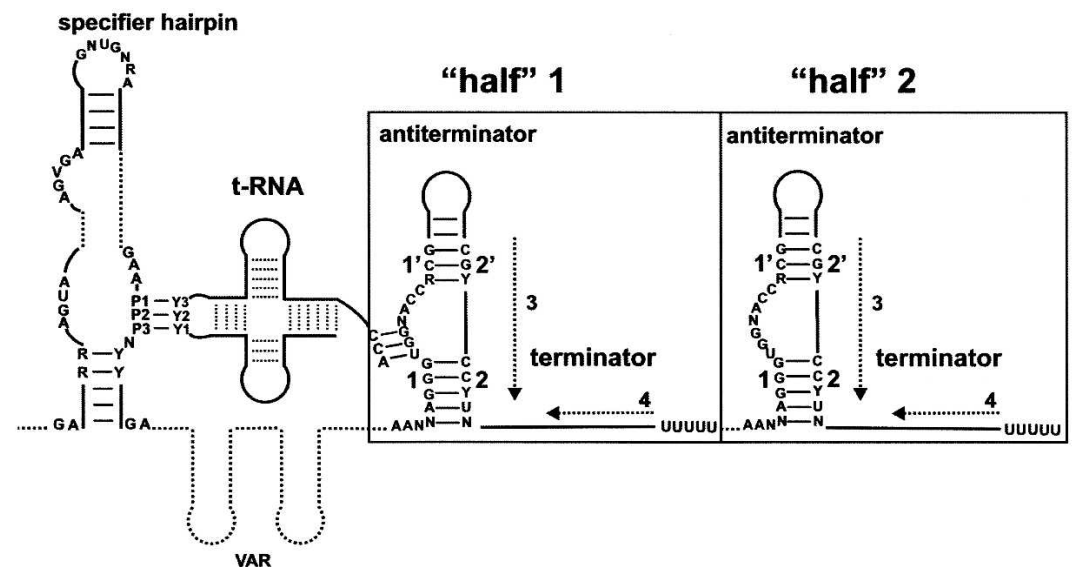

FIGURE 3. Two structurally different types of tandem T-boxes. (A) Double T-boxes (tandemly arranged complete T-boxes) and $(B)$ partially double T-boxes (a specifier hairpin followed by two adjacent antiterminator/terminator structures).

\section{Duplications and expansion of T-box regulons}

T-boxes are often duplicated. In simple cases, close duplicates of aminoacyl-tRNA synthetase T-boxes are observed upstream of biosynthetic or transporter genes. For instance, in $C$. perfringens and C. beijerinckii, the ALA-T-box upstream of the $y u g G H$ (alaRT) operon encoding a candidate alanine transaminase and a transcriptional regulator is likely the result of duplication of the ALA-T-box regulating the alaS gene in the common ancestor of these species (Fig. 5A), whereas ALA-T-boxes upstream of the alaRT operon in other species clearly form a distinct branch (Fig. 5A). It is possible that in this case the duplication caused in situ substitution of the original ALA-T-box (cf. a similar phenomenon on the gene level in the operon dynamics) (Omelchenko et al. 2003).

Sometimes multiple duplications of T-boxes lead to rapid expansion of T-box regulons. Such expansions were observed in the genome of B. cereus and, independently, C. difficile. The duplication of the THR-T-box originally upstream of the thrS gene has led to emergence of new THR-T-boxes upstream of the transporter genes $b r n Q$, $y k b A$ in the former and the biosynthesis genes hom, thrCB in the latter (Fig. 5B). A specific case of T-box duplication is a duplication leading to double or partially double T-boxes. In most cases, the tandem T-boxes are closest relatives of each other (e.g., the tandem THR-Tboxes upstream of the hom gene in $C$. difficile or THR-T-boxes upstream of thrZ in B. cereus) (Fig. 5B).

In another case, we detected the recent expansion of T-box regulon in C. difficile that had occurred after the separation of the Clostridia into individual lineages (Fig. 5C). Multiple duplications of ARG-T-boxes following the loss of the arginine transcription regulator AhrC in C. difficile created five ARG-T-boxes upstream of three biosynthetic and two transporter operons; at that, the original ARG-T-box upstream of the $\operatorname{argS}$ gene was lost (Fig. 5D). Similarly, the loss of the S-box riboswitch regulating methionine biosynthesis in the Lactobacillales has lead to the expansion of MET-T-boxes in the Lactobacillaceae lineage (whereas in the Streptococcus spp. these genes are regulated by a new transcription factor, MtaR/MetR) (Rodionov et al. 2004; Kovaleva and Gelfand 2007; Sperandio et al. 2007).

In some cases, it does not make sense to say which of two duplicated T-boxes is the original one. In several cases, this seems to be caused by disruption of the original operon, where both parts are preceded by descendants of the original T-box. This may be the case for PRO-Tboxes upstream of the proBA and proI operons in $B$. stearothermophilus, as well as B. subtilis and B. licheniformis. These operon pairs are the closest relatives in the phylogenetic tree in the B. stearothermophilus branch and in the node corresponding to the latest common ancestor of $B$. subtilis and B. licheniformis (Fig. 5E). Other genomes have a PRO-T-box upstream of the complete biosynthetic proIBA operon, and this is a likely ancestral state. Duplication of this operon together with the preceding T-box and subsequent loss of the proI gene in one copy and proBA in the other copy would lead to the present state in these three genomes. An alternative scenario is simple operon disruption leading to separation of the proBA and proI genes and the loss of regulation by the latter (as was likely the case for B. cereus). The evolutionary signal does not seem to be sufficient to decide which scenario holds for $O$. iheyensis.

A more complicated example is provided by the hisS-aspS operon. In Lactobacillales, it is regulated by ASP-T-boxes, 


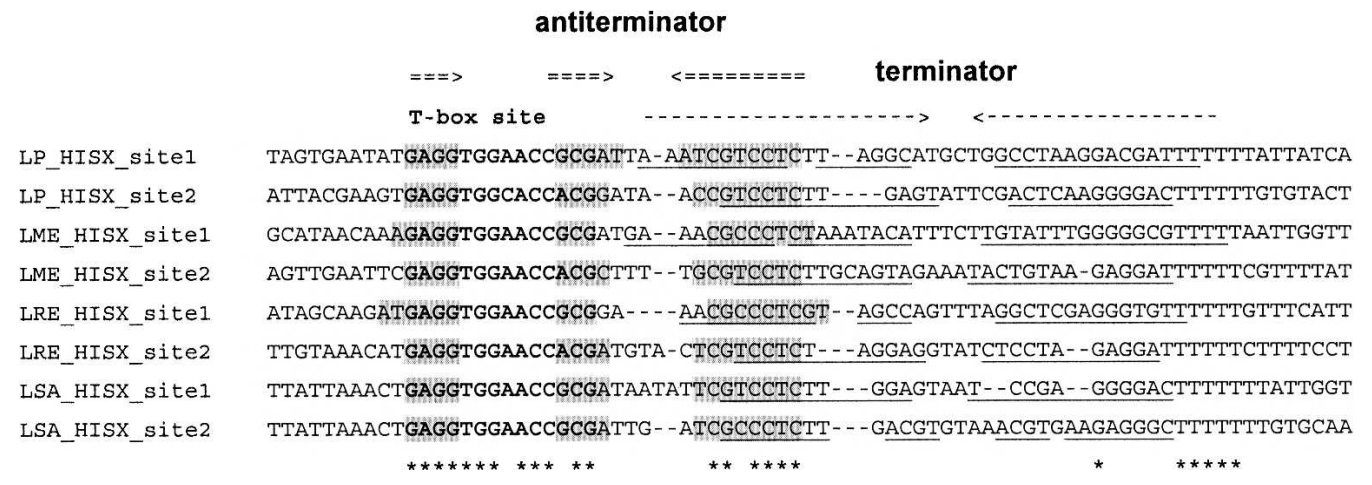

FIGURE 4. Alignment of antiterminator/terminator regulatory regions of the hisXYZ partially double T-boxes in the Lactobacillales. (LP) Lactobacillus plantarum; (LSA) Lactobacillus sakei; (LRE) Lactobacillus reuteri; (LME) Leuconostoc mesenteroides. (Arrows in the upper lines) The complementary stems of alternative antiterminator and terminator structures; (gray background) base-paired positions; $\left(^{*}\right)$ conserved positions; (bold) the conserved T-box site.

whereas in L. reuteri, there are two operons, hisS and aspS, regulated by the HIS- and ASP-T-boxes, respectively; the former is a copy of the latter with a changed specificity (see below for further discussion). Again, the most plausible scenario seems to be operon duplication with subsequent loss of his $\mathrm{in}$ one copy and aspS in the other copy.

\section{Changes of specificity}

Both the vertical mode of evolution and the duplications may be accompanied by changes in the T-box specificity. Here we consider only clear cases, when T-boxes with different specificity are closest relatives of each other. Such changes occur in the subgroups where the amino acids synthesized by adjacent metabolic pathways also have similar codons: the ASP/ASN/HIS group and the branched-chain amino acids group. In these cases, changes are caused by single nucleotide substitutions in the specifier codons. Interestingly, in all cases these substitutions occurred in the first codon positions.

In the Bacillales, the ASP $\leftrightarrow$ ASN specificity changes in the T-box upstream of the hisS-aspS operon are caused by the $\underline{\mathrm{G}} \mathrm{AC} \leftrightarrow \underline{\mathrm{A} A C}$ transitions (Fig. $6 \mathrm{~B}$ ). Based on the analysis of other groups and gene functionality, the ASP specificity seems to be the ancestral one, but such changes seem to have occurred more than once and in both directions. In Lactobacillus johnsonii, the duplicated T-box upstream of an $\mathrm{ABC}$-transporter annotated as a glutamine transporter is an ASP-T-box, although its likely ancestor is the ASN-Tbox upstream of the asnA gene, observed also in other Lactobacillales (Fig. 6A). This also means that the transporter is more likely to be an asparagine (or aspartate) transporter than a glutamine one, and should be renamed aspQHMP. In Pediococcus pentosaceus, a duplicated copy of the ASP-T-box upstream of the annotated asnS2 gene was inserted upstream of a candidate histidine $\mathrm{ABC}$-transporter hisXYZ and changed specificity by the substitution

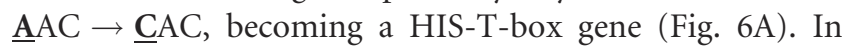
the already mentioned case, in L. reuteri, disruption of the
ASP-T-box-regulated hisS-aspS operon has generated two operons; the hisS operon is now regulated by a HIST-box with the $\mathrm{GAC} \rightarrow \underline{\mathrm{CAC}}$ change of the specifier codon (Fig. 6A).

Another group of T-boxes with obvious specificity changes is the ILE-T-boxes. There, the brnQ subbranch consists of three ILE-T-boxes (Lactobacillus casei, L. johnsonii, L. reuteri) and two VAL-T-boxes (L. casei, $L$. plantarum) (Fig. 6C). The phylogenetic analysis of the protein sequences of the branched-chain amino acid transporter BrnQ shows that genes regulated by ILE-Tboxes form two independent branches. Two VAL-T-boxregulated genes are immediately adjacent to one of these branches. In the T-box tree, all T-boxes on the same branch are ILE-T-boxes, which is likely the ancestral specificity. Thus it seems that simultaneous duplication of the Lactobacillus brnQ genes (creating the genes denoted brnQ2 in Fig. 7) and the upstream T-boxes was followed by a change in the T-box specificity by the $\underline{\mathrm{ATC}} \rightarrow$ GTC $($ ILE $\rightarrow$ VAL) substitution in the specifier codon.

Experimentally studied BrnQ proteins have been shown to transport all three chain amino acids (leucine, isoleucine, and valine) (Stucky et al. 1995; Tauch et al. 1998). It will be interesting to see whether the substrate specificity or affinity of transporters encoded by VAL-T-box-regulated genes is different from that of ILE-T-box-regulated ones. An additional relevant observation is that two $\operatorname{brnQ}$ homologs belonging to different branches are regulated by THR-T-boxes (Fig. 7). In B. cereus, the THR-T-box upstream of $b r n Q$ results from duplication of the THR-Tbox regulating the thrS gene. A more interesting case is the partially double THR-T-box upstream of the brnQbraB1 operon of C. tetani. This T-box is closely related to ILE-Tboxes upstream of $b r n Q$ and some other genes in other Clostridium spp. (Figs. 6C 7). The most parsimonious scenario is that this T-box arose by partial duplication of the ancestral ILE-T-box accompanied by a specificity 

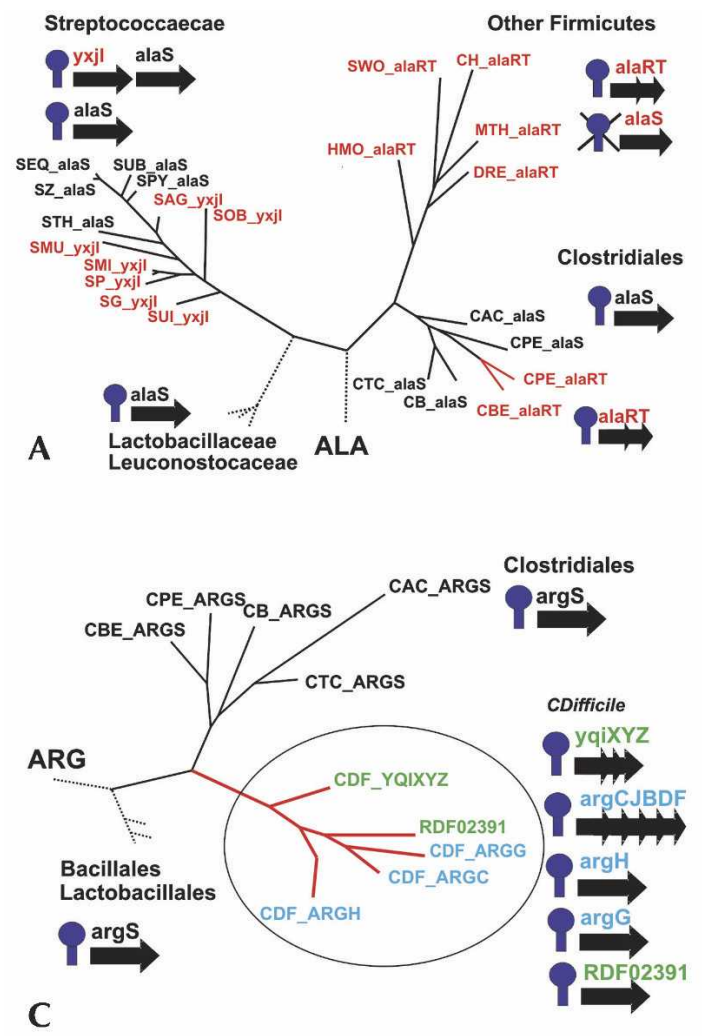

C

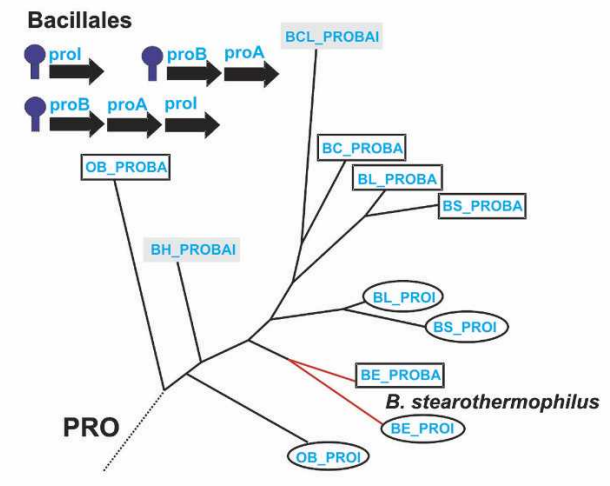

B
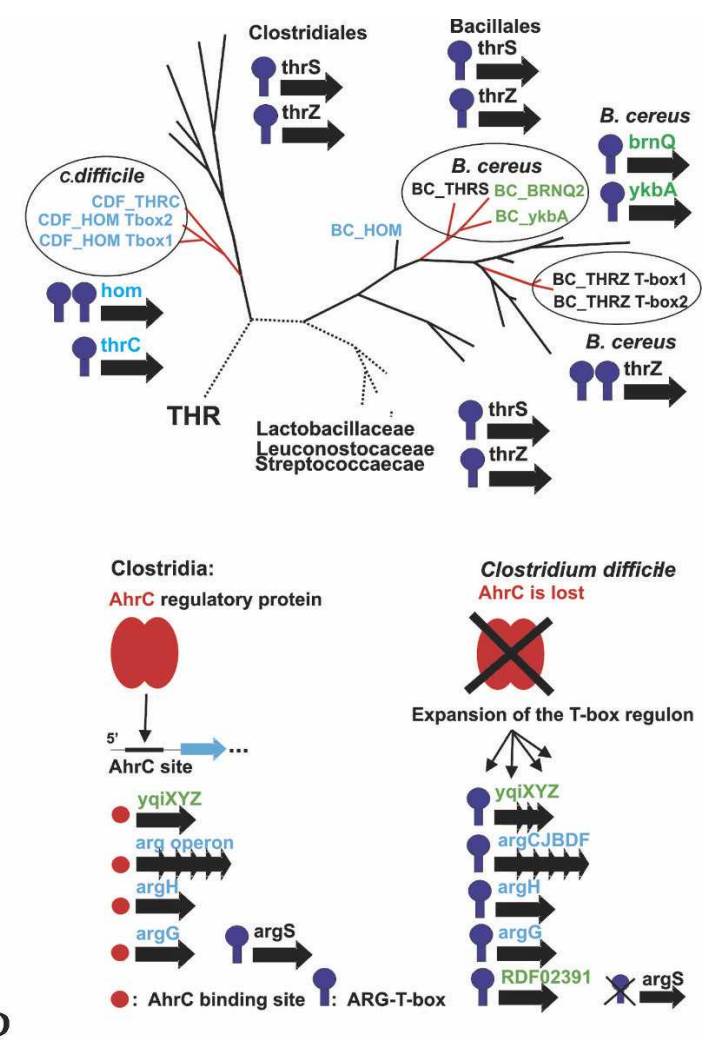

E

FIGURE 5. Duplications of T-boxes. (Filled rectangle with a filled circle above) Schematic RNA structure with T-boxes and (filled black arrows) regulated genes/operons. (Black) Aminoacyl-tRNA synthetase, (blue) biosynthetic, (green) transporter, and (red) other (unknown) genes. (Red or circled) The sub-branches of interest. (A) A fragment of the ALA-T-box phylogenetic tree demonstrating duplication in the Clostridiales. (B) A fragment of the THR-T-box phylogenetic tree. (Circled) The expansions of the T-box regulon in C. difficile, B. cereus, and the T-box duplication leading to double T-boxes (denoted "box1" and "box2"). (C) A fragment of the ARG-T-box phylogenetic tree. (Circled) The branch showing the rapid expansion of the ARG-T-box regulon. $(D)$ The detailed picture illustrating the loss of the regulator AhrC and expansion of the ARG-T-box regulon in $C$. difficile. (E) A fragment of the PRO-T-box phylogenetic tree. T-boxes regulating (rectangles) proBA, (circles) proA, and (filled rectangles) proBAI operons. (Red) The sub-branch corresponding to the recent PRO-T-box duplication in B. stearothermophilus.

change. Again, it is interesting to see what is the substrate specificity of the THR-T-box-regulated transporters.

The final example of this type is the already mentioned duplicated ILE-LEU-T-box upstream of the ilv operon of $D$. reducens, where the LEU-T-box was created by the $\underline{\mathrm{A} T C} \rightarrow \underline{\text { CTC }}$ substitution (Fig. 6C).

\section{Variability of regulation of common} biosynthetic pathways

The fact that homologous transporters may be regulated by T-boxes with different specificity is not surprising, since transporter specificity also is very flexible in evolution. A 


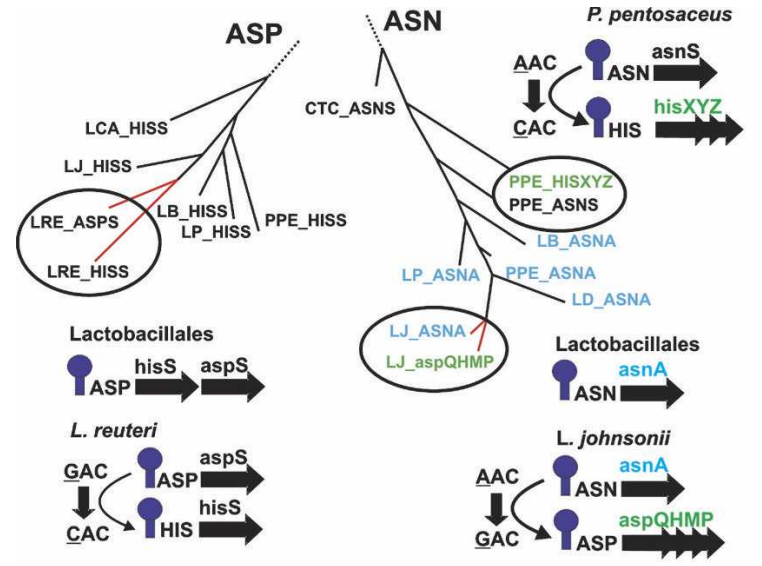

A

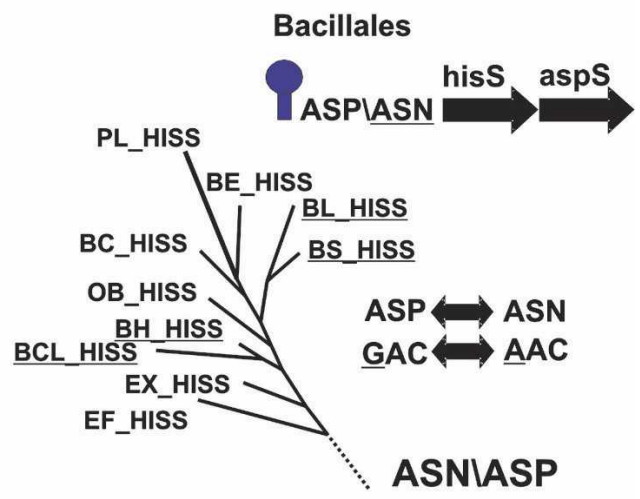

B

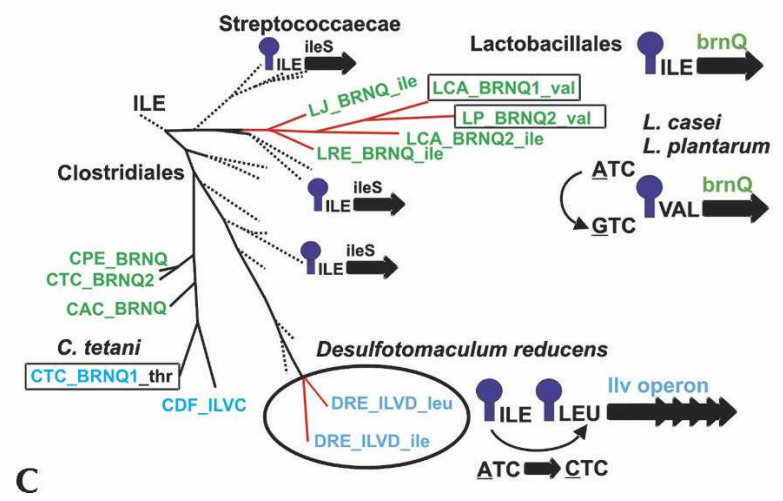

FIGURE 6. Changes of specificity of T-boxes. The notation is as in Figure 5. (A) Fragments of the ASP- and ASN-T-box phylogenetic trees. (Circled) Recent duplications accompanied by changes in the T-box specificity in the same genome or closest relatives. (B) Fragments of the ASPand ASN-T-box phylogenetic tree. ASN-T-boxes are underlined, ASP-T-boxes are not. $(C)$ A fragment of the ILE-T-box phylogenetic tree. (Red) The branch of T-boxes regulating brnQ genes. Recent changes of T-box specificity (ILE $\rightarrow$ VAL) in two closest Lactobacillus relatives (L. casei, L. plantarum). (Rectangles) Two VAL-T-boxes; (circled) the recently duplicated T-boxes (with changed specificity ILE $\rightarrow$ LEU) upstream of the ilv operon of D. reducens.

somewhat more interesting observation is that orthologous genes encoding enzymes common to several biosynthetic pathways may be regulated by T-boxes with specificity corresponding to all terminal products. Again, the clearest examples come from the aromatic and branched-chain amino acid pathways.

The regulation of the aro genes (aromatic amino acid common pathway) depends on the phylogenetic group: the aro genes are regulated by a TYR-T-box in B. cereus, PHET-boxes in the Peptococcaceae, H. mobilis, M. thermoacetica, C. thermocellum, and a TRP-T-box in the Chlorophlexales (within the trp operon). These T-boxes are not similar and thus seem to result from independent acquisitions (data not shown).

Simiarly, the ilv genes (branched-chain amino acid biosynthesis) are regulated by LEU-T-boxes (some Bacillales, Clostridales, S. wolfei), ILE-T-boxes (some Bacillales), a VAL-T-box (C. acetobutylicum), and a double ILE-LEUT-box in D. reducens.

\section{DISCUSSION}

The fact that T-boxes are fairly easy to identify in genomic sequences, and in most cases their specificity can be reliably predicted, allowed us to make a number of tentative functional annotations of hypothetical proteins. In particular, in several cases the existing function was reassigned, for instance, for several transporters whose specificity had been initially annotated purely by sequence similarity to relatively distant homologs.

A more interesting case is that of annotated metS2 of $C$. beijerinckii, which is preceded by a LYS-T-box. The latter is most similar to other LYS-T-boxes, and thus its specificity is likely correctly predicted (data not shown). The encoded protein is only weakly similar to experimentally established methyonyl-tRNA synthetases, and the phylogenetic analysis of the MetS proteins demonstrated that the clostridial MetS2 branch is a distant deeply rooted outgroup. At the same time, C. beijerinckii, like all Clostridia, has the classical 


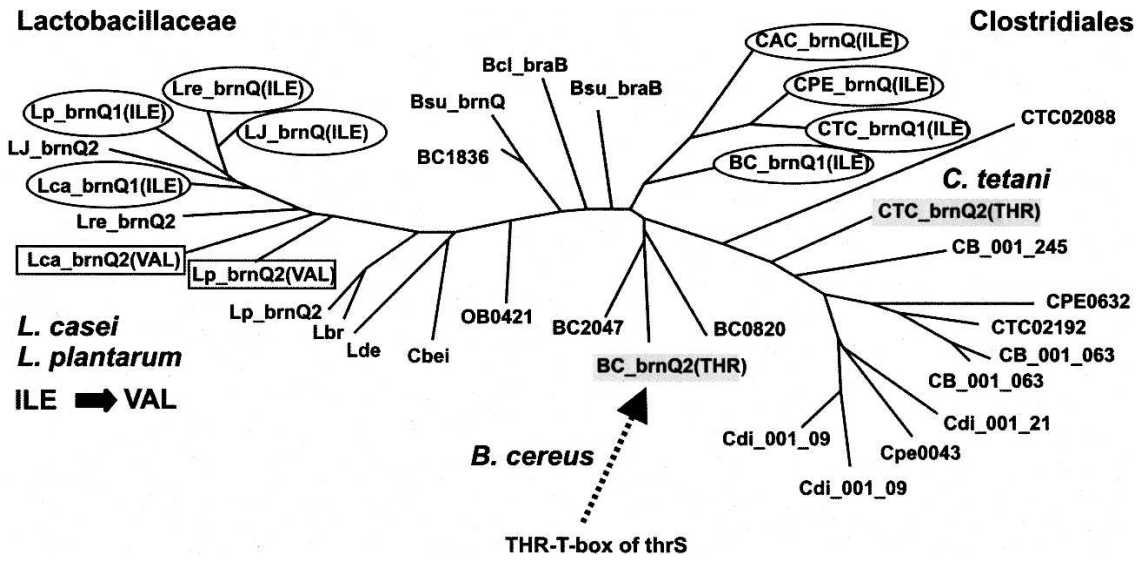

FIGURE 7. Protein phylogenetic tree of branched-chain amino acid transporters ( $b r n Q / b r a B)$. (Circles) Genes regulated by ILE-, (rectangles) VAL-, and (filled rectangles) THR-T-boxes.

codon positions provides for stronger interaction between the tRNA and the specifier codon.

A combination of the tree building approach, analysis of T-box specifier codons, and functional analysis of regulated operon allowed us to reconstruct the events that created the existing T-box regulons in the Firmicutes, using in each case the most parsimonious explanation of the observed T-box distribution (Fig. 8). Of course, this reconstruction is rough and tentative, and its details will need to be reconsidered when more genomes are available and the dynamics of the T-box evolution are better understood. Still, some observations seem to be firmly estab-

metS gene. Thus, we predict that metS2 may encode a new lysyl-tRNA synthetase not homologous to known lysyltRNA synthetases and distantly related to methyonyl-tRNA synthetases. Of course, this is a very tentative prediction that requires experimental verification.

The relationships between T-box specificity and the regulated gene specificity may not be straightforward, as shown by rapid changes of the ASP $\leftrightarrow$ ASN specificity of T-boxes upstream of the hisS-aspS operon. Given that in many species asparaginyl-tRNA is formed by transamidation of aspartyl-tRNA, and asparagynyl-tRNA synthetase is missing (Wolf et al. 1999; Woese et al. 2000), a more detailed study of the relationships between tRNA, aminoacyl-tRNA synthetases, and T-boxes would be interesting.

Another interesting aspect is the choice of the specifier codon among all codons corresponding to a given amino acid. We compared the codon distribution both in T-boxes and in gene-coding regions in the Firmicutes. Predominantly one or two codons are preferred in T-box regulatory sites (Table 5). In most cases, the results showed anticorrelation between the choice of the regulatory codon in T-boxes and the codon frequency in genes. For example, the rarest codon ( $\mathrm{NNC}$ or NNG) is used in all T-boxes corresponding to all amino acids with two codons (PHE, TYR, ASN, ASP, HIS, LYS, CYS) (Table 5). Branched-chain amino acids (ILE, LEU) as well as SER-, THR-, and GLY-Tboxes also use the rarest or one of the rarest codons (Table 5). Two exceptions are ALA- and PRO-T-boxes, which use more frequent codons (NNU) in gene regulation. Thus, rare codons were chosen in T-boxes to regulate most genes in response to the concentration of corresponding uncharged tRNA. One possible explanation is that this makes the regulation more sensitive to changes of amino acid concentrations, similarly to translation-dependent attenuators (Harms et al. 1985; Harms and Umberger 1987; Fang et al. 2000; Elf et al. 2003). An alternative explanation is that the observed preference for $\mathrm{C}$ in the third lished, such as the T-box-dependent regulation of most aminoacyl-tRNA synthetase genes as well as tryptophan and branched-chain biosynthesis and transport genes in the last common ancestor of the Firmicutes, and secondary loss of many T-boxes in the Lactobacillales, and specifically, in the Streptococcaceae.

The evolutionary processes shaping the existent set of T-boxes are duplications providing raw material for evolution, and changes in specificity. As it has been mentioned above, all cases of identifiable changes of T-box specificity involve substitutions in the first codon position. One possible reason for that could be that codons differing in the first position often encode chemically related amino acids synthesized by homologous enzymes or imported by homologous transporters. Thus subtle changes in gene functional specificity following a duplication event may be accompanied by parallel changes in the specificity of the T-box regulating this gene.

The duplications with subsequent fixation may occur at a very fast rate, as demonstrated by the expansion of the ARG-T-box regulon in C. difficile that occurred simultaneously with lineage-specific loss of transcriptional regulation by the arginine repressor AhrC. The mechanism of duplication and selection should be very efficient. Indeed, assuming that duplicated T-boxes do not target upstream regions of specific genes (no mechanism of such targeted T-box insertion is feasible), they are inserted in random regions and then eliminated by selection if incorporated in a wrong place. On the other hand, we have not observed intermediate stages of this process, namely, cases of T-boxes or their identifiable remnants upstream of obviously irrelevant genes. It might be interesting to attempt to estimate the evolutionary parameters of this process, although the available data may be insufficient for that.

Another promising area of further research is modeling of the mechanism of T-box regulation on the level of RNA 


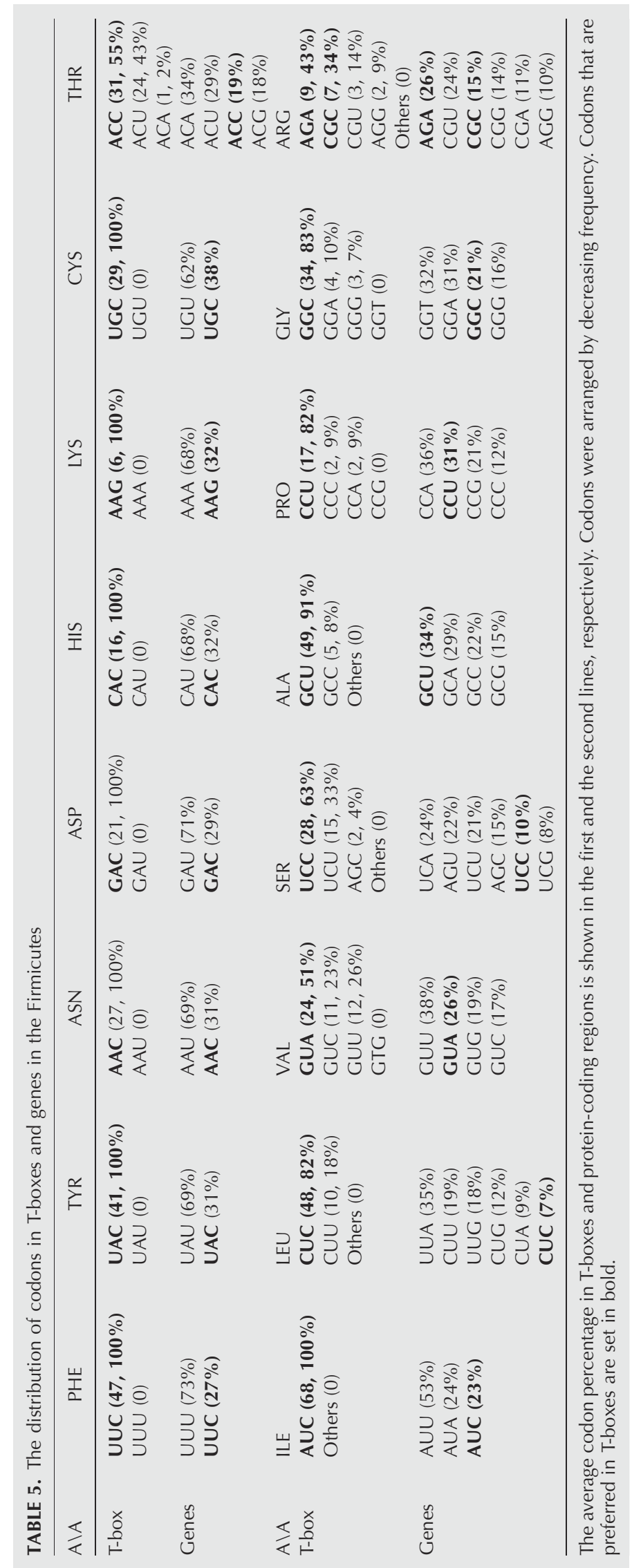




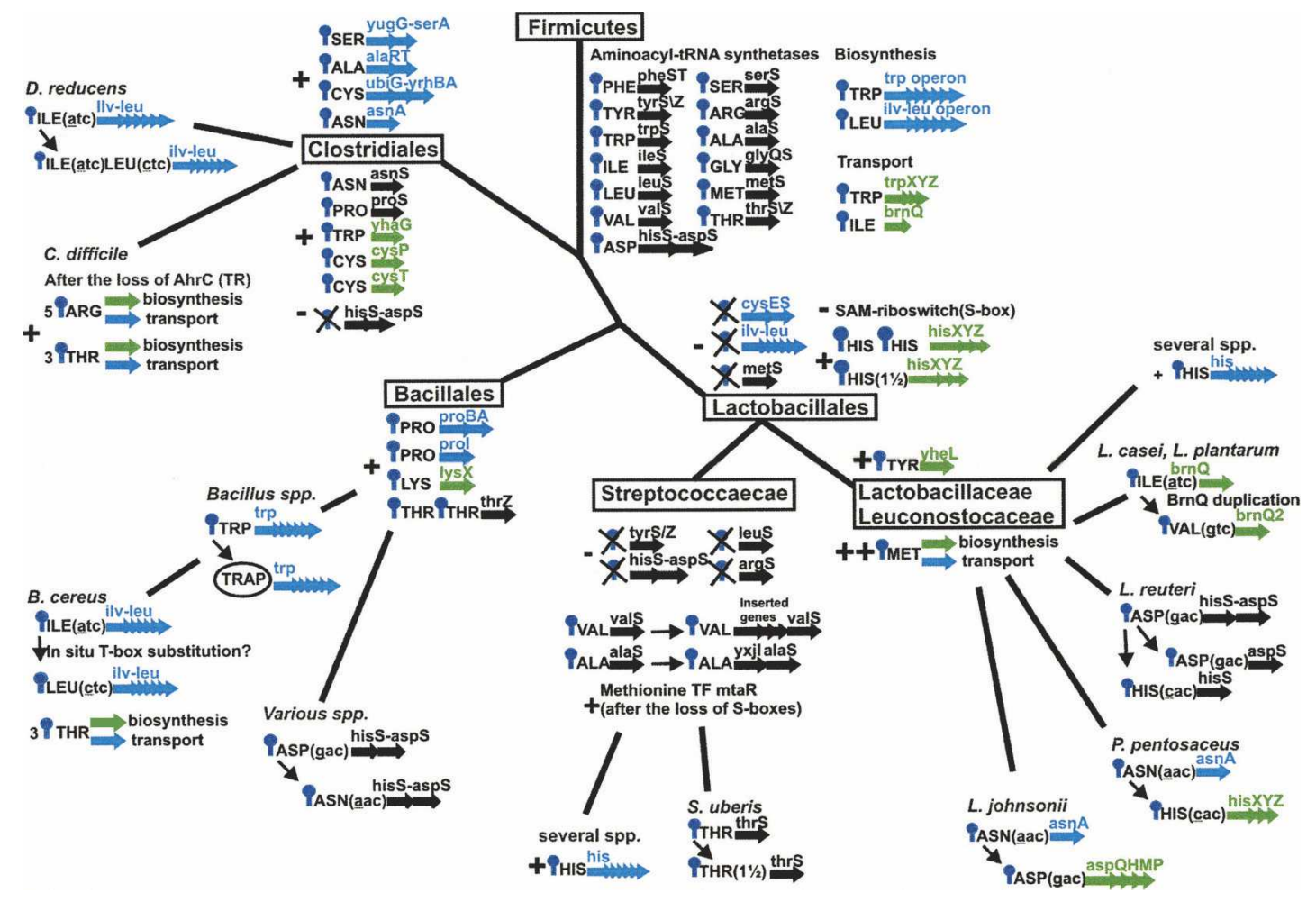

FIGURE 8. The taxonomy tree of most T-box-containing Firmicutes and the evolutionary events reconstructed as the most parsimonious explanation of the observed T-box distribution and phylogenetic relationships. The notation is as in Figure 5. This figure combines the events described in the text and illustrated in Figures 5 and 6. Pluses and minuses denote, respectively, gains and losses of T-boxes and other regulators. Numerous aminoacyl-tRNA synthetase genes, two biosynthetic operons (tryptophan trp and branched-chain amino acids ilv-leu), and two transporter operons (tryptophan $\operatorname{trpXYZ}$ and branched-chain amino acids $b r n Q$ ) were regulated by $\mathrm{T}$-boxes in the ancestral genome. In the ancestor of the Clostridiales, the T-box regulon expanded by several biosynthetic and transporter operons, with additional expansion in C. difficile. In the Bacillales, proline biosynthesis and lysine transporter genes become T-box-regulated, and subsequent lineage-specific specificity changes occurred. In the ancestor of the Lactobacillales, T-box regulation of the cysES, ilv-leu, and metS operons and S-box regulation of methionine metabolism genes was lost. A variety of changes occurred in the Streptococcae, Lactobacillaceae, and Leuconostocaceae, and in specific lineages.

kinetics. At that, specifically interesting are consequences of duplications in situ that may be followed by partial deletion: double and partially double T-boxes. As mentioned above, simple yes-no models of the latter based on discrete models of alternative RNA secondary structure yield a paradoxical conclusion that the gene is never expressed.

Unlike the majority of transcription-regulating T-boxes, the translation-regulating ones may function not only cotranscriptionally, but also regulate expression of already transcribed mRNAs. Thus the kinetic and thermodynamic parameters of such regulation might be different. To our knowledge, none of the translation-regulating T-boxes have been studied in experiment. At that, the new, reduced class of candidate actinobacterial T-boxes is a particularly interesting subject for experimental structural and functional studies.

The problem of relationship between T-boxes and other regulatory systems also deserves detailed scrutiny. In some cases, T-boxes coexist with other systems, regulating different sets of genes. For instance, LYS-T-boxes regulate only some transporters ( $l y s X$ from Bacilalles) and, in rare cases, lysyl-tRNA synthetases, whereas LYS-element (L- box) riboswitches regulate most biosynthesis and transporter genes in Firmicutes (lys $P, l y s X Y, l y s W, y v s H, y c g A$ ) (Grundy et al. 2003; Rodionov et al. 2003; Sudarsan et al. 2003; Winkler et al. 2003). T-boxes may co-regulate genes with transcription factors, for example, ALA-T-boxes and the transcription factor AlaR regulating the alaRT operon (our observations and data in the Subtilist database communicated by A.L. Sonenshein; http://genolist.pasteur. fr/SubtiList/), or with translational regulators, for example, TRP-T-box and TRAP regulating the putative tryptophan transporter $y c b K$ (Valbuzzi and Yanofsky 2001; Babitzke 2004). Moreover, T-boxes may also participate in regulatory cascades, for example, in B. subtilis and B. licheniformis, TRP-T-boxes regulate the $y c z A$ gene encoding an anti-TRAP protein (Valbuzzi and Yanofsky 2001; Chen and Yanofsky 2003).

However, a more interesting situation arises when a regulatory system completely substitutes an ancestral system. Two clear examples of rapid T-box regulon expansions following the loss of original regulatory systems have been observed: MET-T-boxes in Lactobacillaceae (loss of 
S-box riboswitches) (Rodionov et al. 2004), and ARG-Tboxes in C. difficile (loss of the AhrC repressor) (above). It is likely that other cases of lineage-specific T-box expansions, such as THR-T-box expansions in B. cereus and $C$. difficile, also could have been caused by the loss of the original regulatory systems. In other cases, T-box regulation gave way to other regulatory systems. For instance, in some Bacillus spp., the original TRP-T-boxes regulating the trp operon were substituted by the TRAP RNA-binding protein (Sarsero et al. 2000).

In all cases, the phylogenetic analysis clearly indicates that the source of expanded T-box families is T-boxes regulating aminoacyl-tRNA synthetase genes. Indeed, this seems to be the original role of the T-box regulation. Similarly, given the scattered appearance of T-boxes outside the Firmicutes and T-box propensity to duplication, it is likely that T-boxes in other taxonomic groups are the result of horizontal transfer from the Firmicutes. However, the phylogenetic trees (data not shown) indicate that the Tbox-regulated genes in Gram-negative bacteria ( $\delta$-proteobacteria) and other groups outside the Firmicutes were not horizontally transferred from the Firmicutes, and thus the simultaneous transfer of the T-boxes and the currently regulated genes seems unlikely even for aminoacyl-tRNA synthetase genes that are often horizontally transferred (Wolf et al. 1999). At present, it is not clear, whether these T-boxes have entered the new genome alone or they are remains of old amino acid T-box regulons.

Overall, due to the relative ease of recognition and establishing specificity of T-boxes, they provide a unique possibility to study the evolutionary dynamics of regulatory systems in bacteria. We believe that many open problems left by our study might be resolved when more genomic data become available.

\section{MATERIALS AND METHODS}

Complete and partial sequences of bacterial genomes were downloaded from GenBank (Benson et al. 2007). Preliminary sequence data were obtained from WWW sites of the Institute for Genomic Research (http://www.tigr.org), the University of Oklahoma's Advanced Center for Genome Technology (http://www.genome. ou.edu), the Sanger Center (http://www.sanger.ac.uk), and the DOE Joint Genome Institute (http://www.jgi.doe.gov).

The RNApattern program (Vitreschak et al. 2001) was used to identify candidate T-boxes. This is a pattern-matching program that allows one to characterize the input pattern as a combination of the RNA secondary structure and sequence consensus motifs. The input RNA pattern described an RNA motif as a set of the following parameters: the number of helices, the length of each helix, the loop lengths, and description of the topology (mutual arrangement) of helices. These definitions are similar to the approach implemented in the Palingol algorithm (Billoud et al. 1996). The T-box pattern (Fig. 9) was constructed using a training set of known T-boxes (Henkin et al. 1992, 1994; Vander Horn and Zahler 1992; Grundy et al. 1997a; Luo et al. 1997, 1998; Frenkiel et al. 1998; Pelchat and Lapointe 1999; Panina et al. 2003; Rodionov

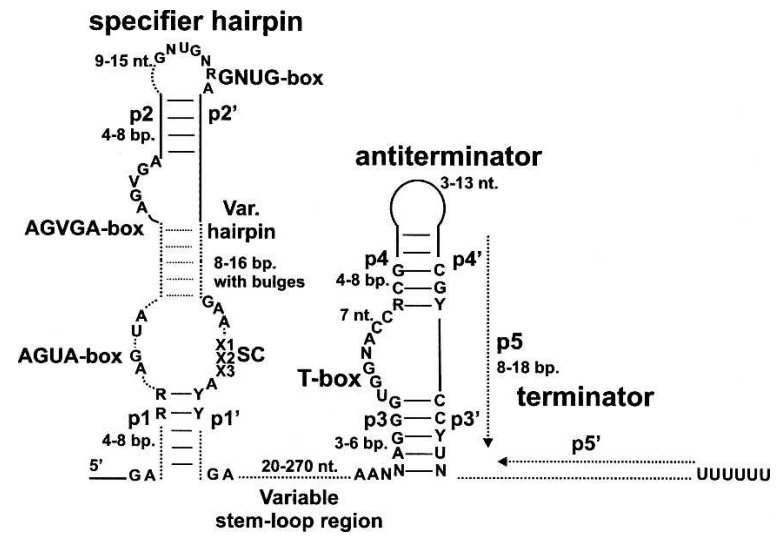

FIGURE 9. The T-box search pattern. The RNA secondary structure stems are numbered P1-P3 (the specifier hairpin), P4-P5 (the antiterminator), and P6 (the terminator). The conserved positions/ boxes and structural-element lengths are shown.

et al. 2003, 2004; Grundy and Henkin 2004; Gutierrez-Preciado et al. 2005) and includes the most conserved structures in T-boxes, namely, the specifier hairpin and the alternative antiterminator/ terminator structures. The identified T-boxes were aligned using the sequence/structure alignment program MultAl (A.A. Mironov, unpubl.) with manual correction, where necessary. The specificity of T-boxes was assigned by inspection of anti-anti-codon regions (specifier hairpin) and validated by construction of phylogenetic trees and functional analysis of regulated genes.

Orthologous proteins were defined by the best bidirectional hits criterion (Tatusov et al. 2001) implemented in the GenomeExplorer program (Mironov et al. 2000). Distant protein homologs were identified using PSI-BLAST (Altschul and Koonin 1998). Multiple protein sequence alignments were constructed using CLUSTALX (Thompson et al. 1997).

Phylogenetic trees of T-boxes and proteins were constructed using the maximum likelihood algorithm implemented in PHYLIP (Felsenstein 1981) and drawn using the GeneMaster program (A.A. Mironov, unpubl.). Only highly conserved regions of T-box alignments, the specifier hairpin, and the terminatorantiterminator region were used.

Candidate operons were defined as sets of genes transcribed in the same direction, with short intergenic spacers and potentially belonging to the same functional subsystem.

\section{SUPPLEMENTAL DATA}

Supplemental material can be found at http://www.rnajournal.org.

\section{ACKNOWLEDGMENTS}

We are grateful to Dmitry Rodionov, Konstantin Severinov, and Alexander Spirin for useful discussions. This study was partially supported by grants from the Howard Hughes Medical Institute (55005610), INTAS (05-8028), and the Russian Academy of Sciences (program "Molecular and Cellular Biology").

Received September 6, 2007; accepted December 31, 2007. 


\section{REFERENCES}

Altschul, S.F. and Koonin, E.V. 1998. Iterated profile searches with PSI-BLAST-A tool for discovery in protein databases. Trends Biochem. Sci. 23: 444-447.

Babitzke, P. 2004. Regulation of transcription attenuation and translation initiation by allosteric control of an RNA-binding protein: The Bacillus subtilis TRAP protein. Curr. Opin. Microbiol. 7: 132139.

Benson, D.A., Karsch-Mizrachi, I., Lipman, D.J., Ostell, J., and Wheeler, D.L. 2007. GenBank. Nucleic Acids Res. 35: D21-D25. doi: 10.1093/nar/gkl986.

Billoud, B., Kontic, M., and Viari, A. 1996. Palingol: A declarative programming language to describe nucleic acids' secondary structures and to scan sequence database. Nucleic Acids Res. 24: 1395-1403. doi: 10.1093/nar/24.8.1395.

Burguiere, P., Auger, S., Hullo, M.F., Danchin, A., and MartinVerstraete, I. 2004. Three different systems participate in L-cystine uptake in Bacillus subtilis. J. Bacteriol. 186: 4875-4884.

Chen, G. and Yanofsky, C. 2003. Tandem transcription and translation regulatory sensing of uncharged tryptophan tRNA. Science 301: 211-213.

Chopin, A., Biaudet, V., and Ehrlich, S.D. 1998. Analysis of the Bacillus subtilis genome sequence reveals nine new T-box leaders. Mol. Microbiol. 29: 662-664.

Delorme, C., Ehrlich, S.D., and Renault, P. 1999. Regulation of expression of the Lactococcus lactis histidine operon. J. Bacteriol. 181: 2026-2037.

Elf, J., Nilsson, D., Tenson, T., and Ehrenberg, M. 2003. Selective charging of tRNA isoacceptors explains patterns of codon usage. Science 300: 1718-1722.

Fang, P., Wang, Z., and Sachs, M.S. 2000. Evolutionarily conserved features of the arginine attenuator peptide provide the necessary requirements for its function in translational regulation. J. Biol. Chem. 275: 26710-26719.

Fauzi, H., Jack, K.D., and Hines, J.V. 2005. In vitro selection to identify determinants in tRNA for Bacillus subtilis tyrS $\mathrm{T}$ box antiterminator mRNA binding. Nucleic Acids Res. 33: 25952602.

Felsenstein, J. 1981. Evolutionary trees from DNA sequences: A maximum likelihood approach. J. Mol. Evol. 17: 368-376.

Frenkiel, H., Bardowski, J., Ehrlich, S.D., and Chopin, A. 1998. Transcription of the trp operon in Lactococcus lactis is controlled by antitermination in the leader region. Microbiol. 144: 21032111.

Gelfand, M.S. 2006. Bacterial cis-regulatory RNA structures. Mol. Biol. 40: $541-550$

Grundy, F.J. and Henkin, T.M. 1993. tRNA as a positive regulator of transcription antitermination in B. subtilis. Cell 74: 475-482.

Grundy, F.J. and Henkin, T.M. 1994. Conservation of a transcription antitermination mechanism in aminoacyl-tRNA synthetase and amino acid biosynthesis genes in Gram-positive bacteria. J. Mol. Biol. 235: 798-804.

Grundy, F.J. and Henkin, T.M. 1998. The S box regulon: A new global transcription termination control system for methionine and cysteine biosynthesis genes in Gram-positive bacteria. Mol. Microbiol. 30: 737-749.

Grundy, F.J. and Henkin, T.M. 2003. The T box and $\mathrm{S}$ box transcription termination control systems. Front. Biosci. 8: 20 31.

Grundy, F.J. and Henkin, T.M. 2004. Kinetic analysis of tRNAdirected transcription antitermination of the Bacillus subtilis glyQS gene in vitro. J. Bacteriol. 186: 5392-5399.

Grundy, F.J., Rollins, S.M., and Henkin, T.M. 1994. Interaction between the acceptor end of tRNA and the T box stimulates antitermination in the Bacillus subtilis tyrS gene: A new role for the discriminator base. J. Bacteriol. 176: 4518-4526.

Grundy, F.J., Haldeman, M.T., Hornblow, G.M., Ward, J.M., Chalker, A.F., and Henkin, T.M. 1997a. The Staphylococcus aureus
ileS gene, encoding isoleucyl-tRNA synthetase, is a member of the T-box family. J. Bacteriol. 179: 3767-3772.

Grundy, F.J., Hodil, S.E., Rollins, S.M., and Henkin, T.M. 1997b. Specificity of tRNA-mRNA interactions in Bacillus subtilis tyrS antitermination. J. Bacteriol. 179: 2587-2594.

Grundy, F.J., Collins, J.A., Rollins, S.M., and Henkin, T.M. 2000. tRNA determinants for transcription antitermination of the Bacillus subtilis tyrS gene. RNA 6: 1131-1141.

Grundy, F.J., Moir, T.R., Haldeman, M.T., and Henkin, T.M. 2002a. Sequence requirements for terminators and antiterminators in the $\mathrm{T}$ box transcription antitermination system: Disparity between conservation and functional requirements. Nucleic Acids Res. 30: 1646-1655.

Grundy, F.J., Winkler, W.C., and Henkin, T.M. 2002b. tRNAmediated transcription antitermination in vitro: Codon-anticodon pairing independent of the ribosome. Proc. Natl. Acad. Sci. 99: 11121-11126.

Grundy, F.J., Lehman, S.C., and Henkin, T.M. 2003. The L box regulon: Lysine sensing by leader RNAs of bacterial lysine biosynthesis genes. Proc. Natl. Acad. Sci. 100: 12057-12062.

Gutierrez-Preciado, A., Jensen, R.A., Yanofsky, C., and Merino, E. 2005. New insights into regulation of the tryptophan biosynthetic operon in Gram-positive bacteria. Trends Genet. 21: 432-436.

Gutiérrez-Preciado, A., Yanofsky, C., and Merino, E. 2007. Comparison of tryptophan biosynthetic operon regulation in different Gram-positive bacterial species. Trends Genet. 23: 422426.

Harms, E. and Umbarger, H.E. 1987. Role of codon choice in the leader region of the ilvGMEDA operon of Serratia marcescens. J. Bacteriol. 169: 5668-5677.

Harms, E., Hsu, J.H., Subrahmanyam, C.S., and Umbarger, H.E. 1985. Comparison of the regulatory regions of ilvGEDA operons from several enteric organisms. J. Bacteriol. 164: 207-216.

Henkin, T.M. 1994. tRNA-directed transcription antitermination. Mol. Microbiol. 13: 381-387.

Henkin, T.M. and Yanofsky, C. 2002. Regulation by transcription attenuation in bacteria: How RNA provides instructions for transcription termination/antitermination decisions. Bioessays 24: 700-707.

Henkin, T.M., Glass, B.L., and Grundy, F.J. 1992. Analysis of the Bacillus subtilis tyrS gene: Conservation of a regulatory sequence in multiple tRNA synthetase genes. J. Bacteriol. 174: 1299-1306.

Hullo, M.F., Auger, S., Dassa, E., Danchin, A., and MartinVerstraete, I. 2004. The metNPQ operon of Bacillus subtilis encodes an $\mathrm{ABC}$ permease transporting methionine sulfoxide, Dand L-methionine. Res. Microbiol. 155: 80-86.

Kovaleva, G.Y. and Gelfand, M.S. 2007. Transcriptional regulation of the methionine and cysteine transport and metabolism in streptococci. FEMS Microbiol. Lett. 276: 207-215.

Luo, D., Leautey, J., Grunberg-Manago, M., and Putzer, H. 1997. Structure and regulation of expression of the Bacillus subtilis valyltRNA synthetase gene. J. Bacteriol. 179: 2472-2478.

Luo, D., Condon, C., Grunberg-Manago, M., and Putzer, H. 1998. In vitro and in vivo secondary structure probing of the thrS leader in Bacillus subtilis. Nucleic Acids Res. 26: 5379-5387. doi: 10.1093/ nar/26.23.5379.

Mandal, M., Lee, M., Barrick, J.E., Weinberg, Z., Emilsson, G.M., Ruzzo, W.L., and Breaker, R.R. 2004. A glycine-dependent riboswitch that uses cooperative binding to control gene expression. Science 306: 275-279.

Marta, P.T., Ladner, R.D., and Grandoni, J.A. 1996. A CUC triplet confers leucine-dependent regulation of the Bacillus subtilis ilv-leu operon. J. Bacteriol. 178: 2150-2153.

Merino, E. and Yanofsky, C. 2005. Transcription attenuation: A highly conserved regulatory strategy used by bacteria. Trends Genet. 21: 260-264.

Mironov, A.A., Vinokurova, N.P., and Gelfand, M.S. 2000. GenomeExplorer: Software for analysis of complete bacterial genomes. Mol. Biol. 34: 222-231. 
Mwangi, M.M. and Siggia, E.D. 2003. Genome wide identification of regulatory motifs in Bacillus subtilis. BMC Bioinformatics 4: 18.

Omelchenko, M.V., Makarova, K.S., Wolf, Y.I., Rogozin, I.B., and Koonin, E.V. 2003. Evolution of mosaic operons by horizontal gene transfer and gene displacement in situ. Genome Biol. 4: R55. doi: 10.1186/gb-2003-4-9-r55.

Panina, E.M., Vitreschak, A.G., Mironov, A.A., and Gelfand, M.S. 2003. Regulation of biosynthesis and transport of aromatic amino acids in low-GC Gram-positive bacteria. FEMS Microbiol. Lett. 222: $211-220$

Pelchat, M. and Lapointe, J. 1999. In vivo and in vitro processing of the Bacillus subtilis transcript coding for glutamyl-tRNA synthetase, serine acetyltransferase, and cysteinyl-tRNA synthetase. RNA 5: $281-289$

Putzer, H., Gendron, N., and Grunberg-Manago, M. 1992. Coordinate expression of the two threonyl-tRNA synthetase genes in Bacillus subtilis: Control by transcriptional antitermination involving a conserved regulatory sequence. EMBO J. 11: 31173127.

Putzer, H., Laalami, S., Brakhage, A.A., Condon, C., and GrunbergManago, M. 1995. Aminoacyl-tRNA synthetase gene regulation in Bacillus subtilis: Induction, repression and growth-rate regulation. Mol. Microbiol. 16: 709-718.

Reig, N., del Rio, C., Casagrande, F., Ratera, M., Gelpí, J.L., Torrents, D., Henderson, P.J., Xie, H., Baldwin, S.A., Zorzan, A., et al. 2007. Functional and structural characterization of the first prokaryotic member of the $\mathrm{L}$-amino acid transporter (LAT) family: A model for APC transporters. J. Biol. Chem. 282: 13270-13281.

Rodionov, D.A. 2007. Comparative genomic reconstruction of transcriptional regulatory networks in bacteria. Chem. Rev. 107: 34673497.

Rodionov, D.A., Vitreschak, A.G., Mironov, A.A., and Gelfand, M.S. 2003. Regulation of lysine biosynthesis and transport genes in bacteria: Yet another RNA riboswitch? Nucleic Acids Res. 31: 67486757. doi: $10.1093 / \mathrm{nar} / \mathrm{gkg} 900$.

Rodionov, D.A., Vitreschak, A.G., Mironov, A.A., and Gelfand, M.S. 2004. Comparative genomics of the methionine metabolism in Gram-positive bacteria: A variety of regulatory systems. Nucleic Acids Res. 32: 3340-3353. doi: 10.1093/nar/gkh659.

Saier Jr., M.H., Tran, C.V., and Barabote, R.D. 2006. TCDB: The Transporter Classification Database for membrane transport protein analyses and information. Nucleic Acids Res. 34: D181-D186. doi: 10.1093/nar/gkj001.

Sarsero, J.P., Merino, E., and Yanofsky, C. 2000. A Bacillus subtilis operon containing genes of unknown function senses tRNATrp charging and regulates expression of the genes of tryptophan biosynthesis. Proc. Natl. Acad. Sci. 97: 2656-2661.

Sekowska, A. and Danchin, A. 2002. The methionine salvage pathway in Bacillus subtilis. BMC Microbiol. 2: 8. doi: 10.1186/1471-2180-2-8.

Seliverstov, A.V., Putzer, H., Gelfand, M.S., and Lyubetsky, V.A. 2005. Comparative analysis of RNA regulatory elements of amino acid metabolism genes in Actinobacteria. BMC Microbiol. 5: 54. doi: 10.1186/1471-2180-5-54

Sperandio, B., Gautier, C., McGovern, S., Ehrlich, D.S., Renault, P., Martin-Verstraete, I., and Guédon, E. 2007. Control of methionine synthesis and uptake by MetR and homocysteine in Streptococcus mutans. J. Bacteriol. 189: 7032-7044.

Stucky, K., Hagting, A., Klein, J.R., Matern, H., Henrich, B., Konings, W.N., and Plapp, R. 1995. Cloning and characterization of $\operatorname{brn} Q$, a gene encoding a low-affinity, branched-chain amino acid carrier in Lactobacillus delbruckii subsp. lactis DSM7290. Mol. Gen. Genet. 249: 682-690.

Sudarsan, N., Wickiser, J.K., Nakamura, S., Ebert, M.S., and Breaker, R.R. 2003. An mRNA structure in bacteria that controls gene expression by binding lysine. Genes \& Dev. 17: 2688-2697.

Sudarsan, N., Hammond, M.C., Block, K.F., Welz, R., Barrick, J.E., Roth, A., and Breaker, R.R. 2006. Tandem riboswitch architectures exhibit complex gene control functions. Science 314: 300-304.
Tatusov, R.L., Natale, D.A., Garkavtsev, I.V., Tatusova, T.A., Shankavaram, U.T., Rao, B.S., Kiryutin, B., Galperin, M.Y., Fedorova, N.D., and Koonin, E.V. 2001. The COG database: New developments in phylogenetic classification of proteins from complete genomes. Nucleic Acids Res. 29: 22-28. doi: 10.1093/nar/29.1.22.

Tauch, A., Hermann, T., Burkovski, A., Krämer, R., Pühler, A., and Kalinowski, J. 1998. Isoleucine uptake in Corynebacterium glutamicum ATCC 13032 is directed by the brnQ gene product. Arch. Microbiol. 169: 303-312.

Thompson, J.D., Gibson, T.J., Plewniak, F., Jeanmougin, F., and Higgins, D.G. 1997. The CLUSTAL_X windows interface: Flexible strategies for multiple sequence alignment aided by quality analysis tools. Nucleic Acids Res. 25: 4876-4882. doi: 10.1093/nar/ 25.24.4876.

Valbuzzi, A. and Yanofsky, C. 2001. Inhibition of the B. subtilis regulatory protein TRAP by the TRAP-inhibitory protein, AT. Science 293: 2057-2059.

van de Guchte, M., Ehrlich, D.S., and Chopin, A. 1998. tRNATrp as a key element of antitermination in the Lactococcus lactis trp operon. Mol. Microbiol. 29: 61-74.

van de Guchte, M., Ehrlich, S.D., and Chopin, A. 2001. Identity elements in tRNA-mediated transcription antitermination: Implication of tRNA D- and T-arms in mRNA recognition. Microbiol. 147: 1223-1233.

van Nimwegen, E. 2003. Scaling laws in the functional content of genomes. Trends Genet. 19: 479-484.

Vander Horn, P.B. and Zahler, S.A. 1992. Cloning and nucleotide sequence of the leucyl-tRNA synthetase gene of Bacillus subtilis. J. Bacteriol. 174: 3928-3935.

Vitreschak, A.G., Mironov, A.A., and Gelfand, M.S. 2001. The RNApattern program: Searching for RNA secondary structure by the pattern rule. In Proceedings of the $3 r d$ International Conference on "Complex Systems: Control and Modeling Problems," pp. 623-625. The Institute of Control of Complex Systems, Samara, Russia.

Vitreschak, A.G., Rodionov, D.A., Mironov, A.A., and Gelfand, M.S. 2004. Riboswitches: The oldest mechanism for the regulation of gene expression? Trends Genet. 20: 44-50.

Weinberg, Z., Barrick, J.E., Yao, Z., Roth, A., Kim, J.N., Gore, J., Wang, J.X., Lee, E.R., Block, K.F., Sudarsan, N., et al. 2007. Identification of 22 candidate structured RNAs in bacteria using the CMfinder comparative genomics pipeline. Nucleic Acids Res. 35: 4809-4819. doi: 10.1093/nar/gkm487.

Welz, R. and Breaker, R.R. 2007. Ligand binding and gene control characteristics of tandem riboswitches in Bacillus anthracis. RNA 13: $573-582$.

Winkler, W.C., Nahvi, A., Sudarsan, N., Barrick, J.E., and Breaker, R.R. 2003. An mRNA structure that controls gene expression by binding S-adenosylmethionine. Nat. Struct. Biol. 10: 701-707.

Woese, C.R., Olsen, G.J., Ibba, M., and Soll, D. 2000. AminoacyltRNA synthetases, the genetic code, and the evolutionary process. Microbiol. Mol. Biol. Rev. 64: 202-236.

Wolf, Y.I., Aravind, L., Grishin, N.V., and Koonin, E.V. 1999. Evolution of aminoacyl-tRNA synthetases-Analysis of unique domain architectures and phylogenetic trees reveals a complex history of horizontal gene transfer events. Genome Res. 9: 689710.

Yanofsky, C. 1988. Transcription attenuation. J. Biol. Chem. 263: 609612.

Yousef, M.R., Grundy, F.J., and Henkin, T.M. 2005. Structural transitions induced by the interaction between tRNA ${ }^{\mathrm{Gly}}$ and the Bacillus subtilis glyQS T box leader RNA. J. Mol. Biol. 349: 273287.

Zhang, Z., Feige, J.N., and Chang, A.B. 2003. A transporter of Escherichia coli specific for L- and D-methionine is the prototype for a new family within the ABC superfamily. Arch. Microbiol. 180: $88-100$. 

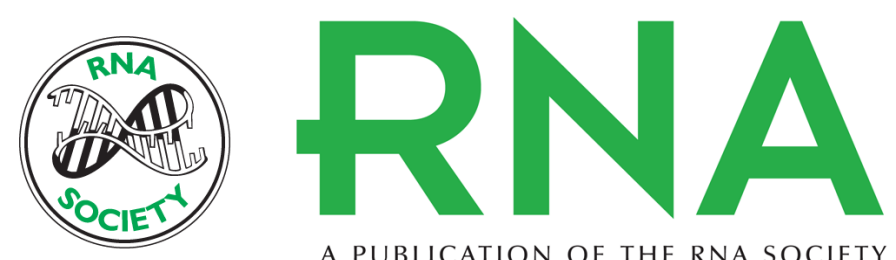

A PUBLICATION OF THE RNA SOCIETY

\section{Comparative genomic analysis of T-box regulatory systems in bacteria}

Alexey G. Vitreschak, Andrei A. Mironov, Vassily A. Lyubetsky, et al.

RNA 2008 14: 717-735

Supplemental
Material http://rnajournal.cshlp.org/content/suppl/2008/03/21/14.4.717.DC1

References This article cites 76 articles, 30 of which can be accessed free at:

http://rnajournal.cshlp.org/content/14/4/717.full.html\#ref-list-1

License

Email Alerting Receive free email alerts when new articles cite this article - sign up in the box at the Service top right corner of the article or click here.

To subscribe to $R N A$ go to:

http://rnajournal.cshlp.org/subscriptions 